\title{
Sensing the Environment With Whiskers
}

Mathew H. Evans, Michaela S.E. Loft, Dario Campagner, and Rasmus S. Petersen

Subject: Sensory Systems Online Publication Date: May 2019

DOI: $10.1093 /$ acrefore/9780190264086.013.226

\section{Summary and Keywords}

Whiskers (vibrissae) are prominent on the snout of many mammals, both terrestrial and aquatic. The defining feature of whiskers is that they are rooted in large follicles with dense sensory innervation, surrounded by doughnut-shaped blood sinuses. Some species, including rats and mice, have elaborate muscular control of their whiskers and explore their environment by making rhythmic back-and-forth "whisking" movements. Whisking movements are purposefully modulated according to specific behavioral goals ("active sensing"). The basic whisking rhythm is controlled by a premotor complex in the intermediate reticular formation.

Primary whisker neurons (PWNs), with cell bodies in the trigeminal ganglion, innervate several classes of mechanoreceptive nerve endings in the whisker follicle. Mechanotransduction involving Piezo2 ion channels establishes the fundamental physical signals that the whiskers communicate to the brain. PWN spikes are triggered by mechanical forces associated with both the whisking motion itself and whisker-object contact. Whisking is associated with inertial and muscle contraction forces that drive PWN activity. Whiskerobject contact causes whiskers to bend, and PWN activity is driven primarily by the associated rotatory force ("bending moment").

Sensory signals from the PWNs are routed to many parts of the hindbrain, midbrain, and forebrain. Parallel ascending pathways transmit information about whisker forces to sensorimotor cortex. At each brainstem, thalamic, and cortical level of these pathways, there are one or more maps of the whisker array, consisting of cell clusters ("barrels" in the primary somatosensory cortex) whose spatial arrangement precisely mirrors that of the whiskers on the snout. However, the overall architecture of the whisker-responsive regions of the brain system is best characterized by multilevel sensory-motor feedback loops. Its intriguing biology, in combination with advantageous properties as a model sensory system, has made the whisker system the platform for seminal insights into brain function.

Keywords: whisker system, somatosensory system, neural coding, trigeminal ganglion, thalamus, brainstem, barrel cortex, whisker mechanics, behavior, mechanosensation, vibrissae 


\section{Introduction}

It may not, perhaps, be generally known that, as far as they have been traced, the whiskers which adorn the upper lip in tygers, panthers, leopards, cats, seals, \&c. are very copiously supplied with nerves; and altogether in a manner which precludes the possibility of our considering them as merely ornamental appendages.

-S. D. Broughton (Broughton, 1823).

In contrast to humans, whose whiskers are reasonably described as "merely ornamental appendages," the long, specialized hairs known as whiskers or vibrissae of many mammals are critically important sense organs. Many mammals, both terrestrial and aquatic, use whiskers to sense their environments. Wild rats and mice live in underground burrows, and being nocturnal or crepuscular they cannot rely on vision in the way that humans do (Ashby, 1972; Krubitzer et al., 2011). Similarly, seals operate in low visibility, aquatic conditions (Dehnhardt et al., 1998). In both cases, highly sensitive whiskers have evolved as a solution. Rats and mice use their whiskers to localize and identify objects (Carvell \& Simons, 1990). Seals use their whiskers to track the turbulent water trails generated by fish as they swim (Dehnhardt et al., 2001).

The whisker system is not only fascinating biologically but is also an important model system for a range of fundamental questions in neuroscience, due to a number of special properties. First, the whisker system of mice, rats, and some whiskered species has an exquisite modular anatomical structure. On the mystacial pad (snout), the follicles of the large whiskers (macrovibrissae) are arranged in a grid structure that within a species is highly stereotyped (Welker \& van der Loos, 1986). At every level of the ascending pathway that conveys sensory information from the brainstem to the cerebral cortex, there are one or more maps of the whisker array (Woolsey \& van der Loos, 1970; van der Loos, 1976; Ma, 1991). In cytochrome oxidase stained sections, each of these maps has modular structure, consisting of an array of dark-stained ovals. Each oval corresponds to a particular whisker, and their spatial arrangement mirrors that of the whisker follicles on the snout. At the level of the brainstem, the modules are known as barrelettes; at that of the thalamus, barreloids and at that of primary somatosensory cortex (S1), barrels. Note, however, that modular cytochrome oxidase staining is not unique to whisker barrels: it is also striking, for example, in star-nosed moles (Catania, 2002). Here, by the term "barrel cortex," we intend the part of S1 devoted to the macrovibrissae. Second, these modules can be visualized in both fixed and living tissue, both in vitro and in vivo (Woolsey \& van der Loos, 1970; Agmon \& Connors, 1991). Third, use of mice enables application of the rich toolkit of molecular genetics. Fourth, since whiskers are large hairs, they can be individually and precisely stimulated and their movement imaged, even in the awake, behaving animal.

As a consequence of these advantageous properties, the whisker system has been the platform for a series of important technical breakthroughs: imaging of dendritic spines (Svoboda et al., 1997); in vivo measurement of membrane potential (Margrie, Brecht, \& 
Sakmann, 2002) including from dendrites (Xu et al., 2012); in vivo imaging of many neurons simultaneously (Stosiek et al., 2003; Peron et al., 2015); nanostimulation of individual neurons (Brecht et al., 2004; Houweling \& Brecht, 2008), and in vivo optogenetic stimulation of cortical populations to drive behavior (Huber et al., 2008). Research using the whisker system has led to substantial insights into fundamental questions, including microcircuitry of neural circuits (Lefort et al., 2009; Feldmeyer et al., 2013); development of sensory circuitry (van der Loos \& Dörfl, 1978; Erzurumlu \& Gaspar, 2012); plasticity in neural circuits (Fox, 1992; Feldman \& Brecht, 2005); pathological rewiring (Cases et al., 1996); encoding of sensory stimuli (Zucker \& Welker, 1969; Petersen, Panzeri, \& Maravall, 2009); neural basis of decision making (von Heimendahl et al., 2007; Yang et al., 2016); and investigation of active sensation and its neural basis (Welker, 1964; Carvell \& Simons, 1995; Prescott, Diamond, \& Wing, 2011). Finally, accumulation of a great deal of information concerning both circuitry, cellular properties, and function has made the whisker-barrel system an attractive target for efforts to model cortical circuitry (Kyriazi, 1993; Sharp, Petersen, \& Furber, 2014) and to build biologically inspired robots (Russell, 1985; Pearson et al., 2011).

The aim of this article is to explain how the best-studied, whisker specialist animals-exemplified by rats and mice-use their whiskers to sense the environment around them.

\section{What Are Whiskers?}

Vibrissæ . . . are used as organs of touch by many of the lower animals.

- Charles Darwin (Darwin, 1871)

Whiskers (or vibrissae) are large hairs found mainly on the snout of almost all mammals (Broughton, 1823; Welker, 1964). One of the few exceptions is in humans. The defining feature of a whisker is that in the skin it is anchored in a large follicle-sinus complex (FSC; see Rice, Mance, \& Munger, 1986). Whisker follicles differ from ordinary hair follicles both in their large size and by the fact that each is surrounded by a doughnut-shaped blood sinus. Thus, a synonym for whisker is sinus hair. Whisker FSCs also have a particularly high density of sensory nerve endings.

Unlike typical body hairs, which are cylindrical, whiskers are (in most but not all species) approximately conical. Size and shape varies greatly. In rats, whiskers taper from a diameter of 50 to $100 \mu \mathrm{m}$ at the base to $<5 \mu \mathrm{m}$ at the tip. Seal whiskers are ten times thicker (Hanke et al., 2010). The shaft of a whisker consists of layers of alpha keratin surrounding a hollow core (Quist, Faruqi, \& Hartmann, 2011). Like all hair, whisker shafts themselves are free of nerve innervation. They serve to convey mechanical forces to mechanosensors located in the FSC.

Whiskered animals possess clusters of whiskers on various parts of the head, as well as on the limbs. These include supraorbital (above the eyes), genal (on the cheeks, posterior to the snout), and sub-mandibular (under the jaw). However, the whiskers that are most 
common and have by far the largest neural representation are the mystacial (greek mystax for moustache) whiskers, anchored in the mystacial pad of the snout. Rats and mice have around 30 large macrovibrissae on either side of their snout, as well as a larger number of smaller microvibrissae near the mouth.

Although most whiskered species including cats, dogs, and seals can probably move their whiskers a little, some species-notably rats and mice but also flying squirrels, gerbils, chinchillas, and hamsters (Welker, 1964)-have a much greater degree of muscular control over their mystacial macrovibrissae. Almost all neuroscientific work on the whisker system has considered the mystacial, macrovibrissa type; and from this point on it is this type of whisker we refer to, unless stated otherwise.

In rats and mice, the whiskers are arranged in a gridlike pattern of five rows (designated A to E from dorsal to ventral). Each row has four to seven whiskers arranged in arcs (columns), increasing in length from anterior to posterior. Most posteriorly, there are four large whiskers ( $\alpha, \beta, \gamma$, and $\delta$ ) that straddle the rows (van der Loos \& Dörfl, 1978). The precise numbers of rows and arcs differs in other species, but the existence of a regular grid arrangement is highly conserved (Welker, 1964; Brecht, Preilowski, \& Merzenich, 1997).

\section{Behavioral Function of Whiskers}

It is a general principle of brain function that mammals devote a high fraction of their cerebral cortex to their most behaviorally important sense organs (Petersen \& Diamond, 2001). In contrast to diurnal whiskered animals such as squirrels-which rely on vision and have a large visual cortex-a substantial proportion of rat/mouse sensory cortex is devoted to the whiskers (Campi \& Krubitzer, 2010).

Rats and mice use their whiskers for a remarkable range of behaviors. In an early study, Vincent showed that rats moved more slowly and made more errors in a maze task if their whiskers were removed (Vincent, 1912). Since then, experiments have shown that whiskers can support localizing objects (Brecht et al., 1997; Knutsen, Pietr, \& Ahissar, 2006; Mehta et al. 2007; O'Connor et al., 2010; Campagner et al. 2019); determining the width of apertures (Krupa et al., 2001); discriminating mechanical vibrations (Fassihi et al., 2014); discriminating textured surfaces (Guić-Robles, Valdivieso, \& Guajardo, 1989); detecting air currents (Yu et al., 2016); crossing gaps (Hutson \& Masterton, 1986; Harris, Petersen, \& Diamond, 1999); and navigating corridors (Sofroniew et al., 2014). Whiskers have also been implicated in swimming (Ahl, 1982), hunting (Favaro et al., 2011) and social interaction (Wolfe, Mende, \& Brecht, 2011).

Much less is known about the functions of the non-mystacial vibrissae. The three submandibular "trident" vibrissae typically contact the ground, have a distinct representation in cortex (Thé et al., 2013), and have been implicated in locomotor behavior (Chorev, 
Preston-Ferrer, \& Brecht, 2016). The carpal vibrissae, found on the wrists, may have a role in climbing (Beddard, 1902).

In aquatic mammals, whiskers can work as underwater sense organs. Swimming fish leave turbulent water trails in their wake. Remarkably, blindfolded seals and sea lions can use their whiskers to detect these trails and hunt for fish (Dehnhardt et al., 2001; Gläser et al., 2011). Seals can also use their whiskers to discriminate object size (Grant et al., 2013), and it is by means of their whiskers that a seal is able to balance a ball on its nose (Milne \& Grant, 2014). Manatees and walruses are thought to use their thick brushlike whiskers for foraging in mud (Reep \& Sarko, 2009). Blue whales have whiskers along their jaws, whose function is unknown.

\section{Whisker Movement and Its Neural Control}

[Vibrissa] movements are so rapid that viewed in real time, the whisker field appears a blur. . as an almost fluidlike mosaic of tactile sensors.

-D. J. Simons (Simons, 1995)

\section{Whisking}

Some mammals have sophisticated muscular control of the whiskers, and rhythmic movement of the whiskers is an important aspect of how they use their whiskers as sensors. Whisking is the characteristic back-and-forth movement of the whiskers. Each cycle is termed a whisk and consists of a forward phase (protraction) followed by a backward phase (retraction) (see Figure 1). Protraction and retraction are controlled by two sets of muscles-extrinsic and intrinsic (reviewed in detail by Haidarliu, 2015). The extrinsic muscles attach the mystacial pad to external skull/cartilage. By contrast, each intrinsic (follicular) muscle connects a pair of whisker follicles within the same row. Contraction of extrinsic muscles moves the entire pad; contraction of intrinsic muscles moves individual whiskers (or whisker pairs). Both extrinsic and intrinsic muscles are innervated by branches of the facial nerve (cranial nerve VII) (Dörfl, 1985). During a whisking cycle, whiskers protract and retract through coordinated contraction of the various muscle groups at different phases of the whisking cycle (Berg \& Kleinfeld, 2003). Protraction involves contraction of both extrinsic protractor and intrinsic muscles. Retraction involves release of spring energy built up in the pad during protraction, together with contraction of extrinsic retractor muscles.

As it explores its environment, a rat or mouse will typically whisk in "bouts" lasting 1-10s (Hill et al., 2008). Within a bout, the frequency of whisking is constant (typically 5-10 Hz for rats, 15-20 Hz for mice). Whisking is not, however, simply the output of a constant oscillator. Whisking frequency varies across bouts. Also, on a timescale of seconds, rats/ mice can vary both the amplitude of whisking (difference between peak protraction and peak retraction) and its setpoint (whisker location at mid-whisk) (Figure 2). While the fre- 
quency of whisking on both sides of the head is the same, animals can independently control the amplitude and setpoint of the left and right whisker arrays (asymmetric whisking). We refer to these variables as whisker control parameters.

Whisking is important for two basic reasons. First, it allows an animal to explore a larger region of space more quickly than it would be able to if its whiskers were moveable only via head movements. Second, as discussed next, rats and mice can adapt their whisking according to specific behavioral demands. This active whisking gives whisking animals considerable extra flexibility.
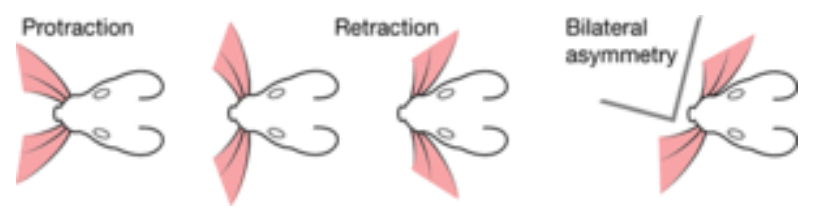

Figure 1. Whisker movements. Many aspects of whisker movement are under active control by rodents. Left: whisking involves the rhythmic backward (retraction) and forward (protraction) movement of the whisker array (macrovibrissae). Right: the two whisker arrays on each side of the head can be positioned independently-for example, when the rat encounters an object.

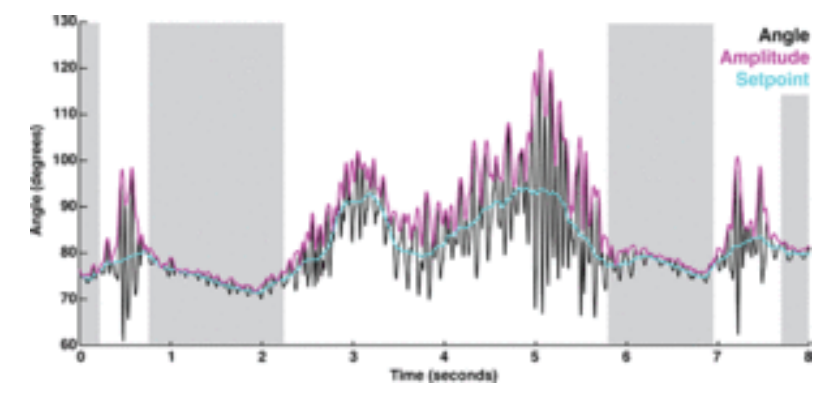

Figure 2. Example of mouse whisking. Whisker angle is measured at the base in head centered coordinates: $0^{\circ}$ points posteriorly, from nose to tail. Three "bouts" of whisking are shown (white background). Within the second bout (2-6s) the mouse gradually increases the amplitude of whisking (difference between peak protraction and peak retraction, purple) and moves the setpoint (whisker location at midwhisk, cyan) anterior.

Source: Campagner et al. (2019).

\section{Whisking as Active Sensation}

In a passive task, such as discriminating the frequency of a buzzer applied to the skin, a stimulus is imposed on each trial, and the brain has to do its best to decode the resulting sensory input. Such tasks have the important advantage of a high degree of experimental control and are useful to address some questions of neural coding. However, under natural conditions, sensing of most kinds is an active process where organisms use motor con- 


\section{Sensing the Environment With Whiskers}

trol of a sense organ to facilitate sensation (Gibson, 1962; Prescott et al., 2011). In vision, Yarbus (1967) famously showed that the eye movements we make across a picture differ depending on the task at hand: for example, when estimating the ages of people in a scene compared to remembering their positions. Similarly, the way we use our hands to gauge the texture of an object is different to the way we use them to gauge its size (Lederman \& Klatzky, 1987).

There are different ways in which sensing can be active. The whisker system, along with human vision and touch, is active not only in the sense that it involves movement but also in the more profound sense that the organism purposefully controls this movement to achieve particular behavioral goals. This distinction is illustrated by the observation that one strategy of active whisking is not to move the whiskers at all. When trained to determine the location of a pole, rats and mice make large, exploratory whisking movements (Mehta et al., 2007; O'Connor et al., 2010). But when trained to discriminate the amplitude of a vibration (Fassihi et al., 2014), they keep their whiskers still. These situations have been called "generative mode" and "receptive mode" respectively (Diamond \& Arabzadeh, 2013).

Purposeful control of whisker movement is achieved by tuning the whisker control parameters discussed above. Switching between generative and receptive mode uses whisking amplitude as a control parameter. Other tasks and behaviors illustrate the control of whisking setpoint. When exploring a new environment, prior to turning its head to the left, a rat typically brings the setpoint of its right whiskers forward (Towal \& Hartmann, 2006). When running, rats and mice move the setpoint of their whiskers forward to point the whiskers directly ahead and reduce whisking amplitude (Arkley et al., 2014;

Sofroniew et al., 2014): the whiskers may be functioning like an early warning system for collisions. Control of setpoint is also illustrated by object localization tasks (Mehta et al., 2007; O'Connor et al., 2010). Early in training, mice attempting to discriminate whether a pole is in one of two locations initially make high amplitude whisker movements that contact the pole at both locations, resulting in somewhat ambiguous sensory signals. With training, however, the mice learn to adjust the whisking setpoint and amplitude so that contact occurs primarily at only one pole location. In this way, by tuning whisking to the task, mice can effectively enhance the discriminability of the stimuli.

Active whisking is dynamic: animals can rapidly change their control strategy in response to unexpected events. In particular, an unexpected whisker-object collision halts protraction, interrupting the whisking rhythm and ensuring that subsequent touches are softer (Mitchinson et al., 2007). If the contact is encountered on one side of the head, whisking amplitude is reduced and setpoint moves backward on that side but forward on the contralateral side (bilateral asymmetry). As a rat makes multiple touches on a surface, the posterior arcs of whiskers are increasingly brought forward-reducing the spread of the whisker array (the difference in angle between the anterior and posterior whiskersGrant et al., 2009). Together these contact-induced modulations of whisking bring more whiskers to bear on an object of interest, while keeping touch strength (see section "Mechanical Forces Underlying Whisker Sensation") within a narrow range. The strategy has

Page 7 of 39

PRINTED FROM the OXFORD RESEARCH ENCYCLOPEDIA, NEUROSCIENCE (oxfordre.com/neuroscience). (c) Oxford University Press USA, 2020. All Rights Reserved. Personal use only; commercial use is strictly prohibited (for details see Privacy Policy and Legal Notice). 
been termed "Minimal Impingement, Maximal Contact" (Mitchinson et al., 2007). Analogously to constriction of the pupil of the eye on a sunny day, this may act as a gain control mechanism.

\section{Neural Control of Whisking}

The cell bodies of the motoneurons that innervate the whisking muscles are located in the lateral facial nucleus (FN) of the brainstem. The FN contains a "myotopic" map of the mystacial pad musculature. Motoneurons with cell bodies in dorsolateral and lateral FN innervate the extrinsic muscles; those in the lateral-medial part, the intrinsic muscles (Takatoh et al., 2013; Deschênes et al., 2016). Each intrinsic muscle is innervated by 50 FN motoneurons (Klein \& Rhoades, 1985). Whisking is one of many orofacial behaviorsbreathing, chewing, licking, and swallowing - that must be coordinated to prevent lethal blockages of the throat (Moore, Kleinfeld, \& Wang, 2014).

Whisking persists after section of the intraorbital (whisker sensory) nerve (Gao, Bermejo, Zeigler, 2001). This is the hallmark of a central pattern generator (CPG): an oscillator driven by endogenous neural activity not reliant on sensory feedback. Since whisking persists after lesion of large parts of the cerebral cortex (Semba \& Komisaruk, 1984), even after decerebration (Lovick, 1972), the whisking CPG circuit has long been suspected to be located in the brainstem. Recently, the CPG has been localized to a brainstem structure presynaptic to the $\mathrm{FN}$ - the whisker-related region of the intermediate reticular formation (wIRT, Moore et al., 2013). Injection of kainic acid into the wIRT induces whisking, whereas lesioning the wIRT abolishes it. Whisking is coordinated with breathing through connections from breathing CPGs in the pre-Böztinger complex to the wIRT (Deschênes et al., 2016).

Parts of the cortex and midbrain are also able to influence whisking. Electrical microstimulation of whisker motor cortex (wM1), even of single neurons, modulates whisker movements (Hall \& Lindholm, 1974; Li \& Waters, 1991; Brecht et al., 2004). wM1 projects to the facial motor nucleus of the brainstem both directly (Grinevich, Brecht, \& Osten, 2005) and indirectly, via brainstem structures (Hattox, Priest, \& Keller, 2002) and superior colliculus (Miyashita, Keller, \& Asanuma, 1994). The activity of wM1 neurons correlates with both fast (phase) and slow (amplitude, setpoint) parameters of whisker movements (Hill et al., 2011; Huber et al., 2012). This encoding is robust to transection of the infraorbital (sensory) nerve, suggesting that the representation of whisking in wM1 is centrally generated and not reafferent.

Box: High-Speed Imaging and Tracking

It is hard to study neural coding in a system without precise knowledge of sensory input, and it is hard to study strategies of motor control without precise measurements of effector movement. In the awake behaving mouse/rat, this has been a challenge, since animals move their whiskers at high speed (up to $\sim 20,000^{\circ} / \mathrm{s}$, Bale et al., 2015) and actively gen- 
erate sensory input via whisker-object collisions. The development of sensors, high-speed cameras and related machine vision algorithms has, therefore, been a crucial advance.

High temporal resolution $(\sim 1000 \mathrm{~Hz})$ measurement of whisker position with respect to the head is possible with CCD arrays or beam-break sensors (Bermejo, Houben, \& Zeigler, 1998; Bermejo, Vyas, Zeigler, 2002; Arabzadeh, Zorzin, \& Diamond, 2005; Wolfe et al. 2008; Jadhav, Wolfe, \& Feldman, 2009; Khatri et al., 2009). It has long been possible also to capture whisker movement with high-speed video (Welker, 1964), but for a long time the need to measure whisker position (angle) from such images manually was a severe bottleneck: electromyogram (EMG) of whisking muscles was used as a proxy (Fee, Mitra, \& Kleinfeld, 1997). In the earliest video-based work, Carvell \& Simons (1990) quantified whisker angle with respect to the head by placing a transparency over a video monitor and tracing the whisker by hand, frame by frame. Later work introduced computer-assisted tracing (Carvell \& Simons, 1995; Mitchinson et al., 2007; Grant et al., 2009), automated tracking of spots of dye painted on whiskers (Knutsen, Beiss, \& Ahissar, 2008; Venkatraman et al., 2009; Nashaat et al., 2017) and semi-automated segmentation of whiskers using machine vision algorithms known as whisker tracking (Knutsen et al., 2005; Voigts, Sakmann, \& Celikel, 2008; Ritt, Andermann, \& Moore, 2008; Perkon et al., 2011).

While measurement of whisker position measurements has advanced our understanding of whisker movement, it does not provide information about whisker shape. This is important since, from whisker shape, it is possible to estimate the mechanical forces acting upon the whiskers (Birdwell, 2007; Pammer, 2013; reviewed by Campagner et al., 2018), and these forces constitute the fundamental physical signals that drive mechanotransduction in the system (see section "Mechanical Forces Underlying Whisker Sensation"). A significant development, therefore, has been that of machine whisker trackers that can extract both whisker position and whisker shape from high-speed (1,000 frames/s) video (Bale et al., 2015; Campagner et al., 2016; Clack et al., 2012). It is now feasible to analyze 1 to 10 million video frames in a reasonable amount of time. Using a head-fixed mouse preparation, whisker tracking can be combined with electrophysiological recording or imaging of neural activity, enabling the neural basis of whisker-mediated behavior to be investigated in greater depth than was previously possible (reviewed by Campagner et al., 2018).

\section{Anatomical Organization of the Whisker Sys- tem}

It is common to characterize the sensory and motor systems of the brain in terms of ascending and descending pathways. In the whisker system, ascending, trisynaptic pathways convey sensory signals from mechanoreceptors in the whisker follicles, via the trigeminal nuclei of the brainstem and ventroposterior/posterior thalamus, to the S1 cortex (also to Secondary Somatosensory Cortex, S2, and M1). Descending pathways can be traced from motor cortex, via brainstem motor areas, as well as SC and cerebellum, to the facial nucleus. However, there are also other parts of the brain-including the stria- 
tum, cerebellum, and zona incerta-that exhibit neural activity that correlates with whisker stimulation and/or the whisking rhythm (Bosman et al., 2011). The interconnectivity of all these areas is much more complex than the notion of ascending and descending pathways might suggest (Figure 3A). In the following sections we first describe the ascending pathway and then give an outline of the broader architecture.
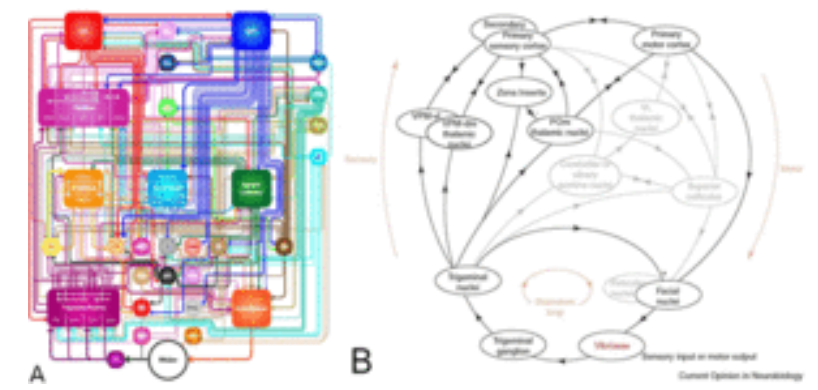

Figure 3. Whisker system architecture. (a) Schematic representation of whisker system connectivity, from Bosman et al. (2011): Amb, ambiguus nucleus; Amg, amygdala; APT, anterior pretectal nucleus; Clau, claustrum; DMN, deep mesencephalic nucleus; $\mathrm{DR}$, dorsal raphe nucleus; EPN, entopeduncular nucleus; GP, globus pallidus; IO, inferior olive; KF-PC, Kölliker-Fuse nucleus and parabrachial complex; LC, locus coeruleus; LD, laterodorsal nucleus; MeV, mesencephalic trigeminal nucleus; NBM, nucleus basalis magnocellularis; NRTP, nucleus reticularis tegmenti pontis; NXII, hypoglossal nucleus; PAG, periaqueductal gray; PN, pontine nucleus; Pom, medial posterior nucleus; PPTg, pedunculopontine tegmental nucleus and the laterodorsal tegmental nucleus; PrV, principal trigeminal nucleus; $\mathrm{RF}$, pontomedullar reticular formation; RN, red nucleus; RT, reticular nucleus; $\mathrm{SNc}$, substantia nigra pars compacta; $\mathrm{SNr}$, substantia nigra pars reticulata; SpVc, spinal trigeminal nucleus pars caudalis; SpVi, spinal trigeminal nucleus pars interpolaris; $\mathrm{SpVo}$, spinal trigeminal nucleus pars oralis; STN, subthalamic nucleus; TG, trigeminal ganglion; TMN, tuberomammillary nucleus; VPM, medial venteroposterior nucleus; wM1, whisker motor cortex; wS1, barrel cortex; wS2, whisker part of the secondary somatosensory cortex; ZI, zona incerta. (b) Partial connectivity diagram illustrates the nested loop architecture of the whisker system, from Kleinfeld et al. (2006). Brainstem and thalamocortical pathways are in black, cerebellar pathways are in gray.

\section{Ascending Sensory Pathways}

The origin of the ascending whisker pathways is the trigeminal ganglion (TG). The TG is located in a depression at the base of the skull outside the brain itself. TG contains cell bodies of the primary sensory neurons that give rise to the trigeminal nerve (cranial nerve V). Primary neurons are pseudounipolar cells, each of which exudes a single axon that splits into two branches-peripheral and central. A subset of these TG cells consists 


\section{Sensing the Environment With Whiskers}

of primary whisker neurons (PWNs). The peripheral branches of PWNs travel, via the infraorbital branch of the trigeminal nerve, to the mystacial pad and terminate as nerve endings in the whisker FSCs. Each PWN innervates a single whisker and a single nerve ending type (Zucker \& Welker, 1969; Rice, Mance, \& Munger, 1986; Tonomura et al., 2015). Each whisker is innervated by 100 to 200 PWNs (Rice et al., 1986; Lee \& Woolsey, 1975). Unlike S1, TG does not have a barrel-like organization: there is only a loose relationship between the location of a PWN within the TG and the whisker it innervates (Leiser \& Moxon, 2006).

The PWNs project, via their central branches, to the trigeminal complex of the brainstem. This complex is conventionally divided into four nuclei: the principal nucleus (PrV) and three spinal nuclei (oral SpVo, interpolar SpVi and caudal SpVc), although an additional area $(\mathrm{SpVm})$, located between $\mathrm{SpVi}$ and $\mathrm{SpVc}$ has also been distinguished (Matthews et al., 2015). PWN central axons course through the trigeminal nuclei, distributing multiple collaterals. In this way, mechanosensory input from the whiskers is conveyed in parallel to multiple brainstem nuclei.

From the trigeminal nuclei, there are multiple disynaptic routes to the cerebral cortex. The lemniscal pathway projects from PrV through the dorsomedial part of the ventroposterior medial nucleus of the thalamus (VPM) to the barrels of primary somatosensory cortex (S1). The extralemniscal pathway projects from caudal SpVi through ventrolateral VPM to both the septa between the barrels and secondary somatosensory cortex (S2). The paralemniscal pathway projects from rostral SpVi through the posterior medial thalamic nucleus (POM) to both S1 (septa of layer 4 and layer 5a), S2 and M1. Three other brainstem-thalamic-cortex pathways have also been identified (for a more detailed account, see Bosman et al., 2011).

However, it is important to recognize that these ascending pathways constitute only a fraction of the routes that signals originating in the trigeminal nuclei might potentially take through the brain (Figure 3A). Each component of the whisker system projects in divergent fashion to several areas. The trigeminal nuclei project to other brain areas in addition to the thalamus, and the POM thalamus projects to other areas in addition to the cerebral cortex. It is also necessary to consider interconnectivity with the constituents of the motor system. The full architecture of the whisker system is better captured by the concept of nested feedback loops.

\section{Loop Architecture}

A useful way to conceptualize the rich interconnectivity of the brain areas associated with the whisker system is in terms of nested pathways that connect the sensory trigeminal nuclei to the FN (Figure 3B). Since FN motoneurons control whisking and whisking leads to activation of mechanoreceptors (via the whisking and contact associated forces as discussed in MECHANICAL BASIS OF WHISKER SENSING AND MECHANORECEPTION), these pathways can be considered to be feedback loops. The sign of the feedback (positive or negative) in any given loop depends on the neurotransmitters involved. The follow- 
ing description is intended to convey the principle of looped architecture but is not exhaustive (for a more detailed account, see Kleinfeld et al., 1999; Bosman et al., 2011).

The most direct loop involves a one synapse, excitatory pathway from the spinal trigeminal nuclei (especially SpVm) to FN (Nguyen \& Kleinfeld, 2005; Matthews et al., 2015). Here, raw PWN activity is routed directly to the whisker motoneurons: this positive feedback loop may serve to heighten muscle tone in response to whisker-object contact. Successively longer loops can be traced via structures in the midbrain and forebrain. There is a midbrain loop from the trigeminal nuclei through SC to FN; a cerebellar loop from the trigeminal nuclei through the cerebellar system (pontine nuclei, inferior olive, and cerebellum) and SC to FN. In addition, there are a series of transcortical loops. The thalamocortical ascending pathways discussed above route sensory signals to S1, S2, and M1. Loops through S1 close via descending pathways to the trigeminal nuclei, to SC, to the cerebellar system, to striatum and to M1. There is also a direct projection from POM thalamus to striatum (Alloway et al., 2017). From M1, loops are also closed via descending projections both to SC and to the premotor brainstem regions that control the whisking rhythm.

Lesion studies indicate that subcortical loops can sustain some behaviors, whereas transcortical loops are necessary for others. Even in the absence of cortex, rats can still whisk (Semba \& Komisaruk, 1984; Gao et al., 2003). In the absence of S1 cortex, rats retain normal sensitivity to both the onset and frequency of air puff-induced oscillations (Hutson \& Masterton, 1986). In contrast, after S1 lesions, rodents can no longer discriminate either the size of gaps in the floor (Hutson \& Masterton, 1986), aperture width (Krupa et al., 2001), rough from smooth textures (Guic-Robles et al., 1992), or the location of a pole (O’Connor et al., 2010).

\section{Mechanical Basis of Whisker Sensing and Mechanoreception}

To understand how whiskers are used to guide behavior, it is fundamental to consider what information they provide to the brain. At the first neural stage of any sensory system are receptors that transduce physical signals from the environment (mechanical, electromagnetic, thermal, or chemical) into corresponding fluctuations of neuronal membrane potential. In the whisker system, these physical signals are mechanical forces acting on mechanotransductive cells embedded within the whisker follicle. In this section, we consider the nature of the relevant forces, how they are transduced and how they influence neuronal activity.

\section{Mechanotransduction and Mechanoreceptors}

Mechanotransduction underlying gentle touch depends on low-threshold mechanoreceptors. In mammals, a major role is played by the Piezo2 ion channel (Coste et al., 2010; Ranade et al., 2014). Piezo2 can sustain mechanically activated currents. It is expressed 
both in the membrane of nerve endings located within the skin, including the whisker FSC, and in that of at least one touch-related accessory cell-the Merkel cell (Ikeda et al., 2014; Maksimovic et al., 2014; Ranade et al., 2014; Woo et al., 2014). Knock-out of Piezo2 substantially attenuates the responses of mice in behavioral tests of gentle touch. It is not understood exactly how Piezo2 converts mechanical force into an electrochemical signal. However, in contrast to vision, taste and smell, the latency of mechanically activated currents is generally too short to be mediated by a biochemical pathway (Corey \& Hudspeth, 1979). Instead, it is likely that Piezo2 is directly gated by mechanical force.

Whisker follicles have the same basic structure across species, although there are some differences in innervation (described in detail by Rice et al., 1986; Ebara et al., 2002). A whisker follicle is surrounded by a blood sinus, all of which is encased in a cartilaginous capsule. The follicle is innervated by both small caliber fibers-likely to have largely noiceptive/thermoreceptive functions-and large caliber fibers-typical of low-threshold mechanoreceptors. The most densely innervated part of the follicle is the level of the upper chamber of the sinus (ring sinus). When a whisker is deflected, these tissues are deformed (Whiteley et al., 2015), likely triggering mechanotransduction via Piezo2-dependent mechanisms (Ikeda et al., 2014; Ranade et al., 2014). At the ring sinus level, the follicle consists of four cell layers between hair shaft and sinus: immediately surrounding the shaft is an inner root sheath; then there is the outer root sheath, glassy membrane, and mesenchymal sheath. Attached to the latter, and dangling within the sinus, is a cartilaginous appendage known as the ringwulst. Within these ring sinus cell layers, three classes of (large caliber fiber) nerve endings are normally distinguished on the basis of morphology. The outer root sheath contains nerve endings that abut onto Merkel cells; the mesenchymal sheath contains lanceolate endings oriented parallel to the whisker shaft, as well as clublike endings closely associated with the ringwulst (Tonomura et al., 2015). At other levels of the follicle, additional types of (large caliber fiber) nerve endings occur. Near the skin surface (rete ridge collar), there are Merkel endings. In the deeper part of the follicle, at the level of the lower (cavernous) chamber of the sinus, there are additional types (in rat, reticulate, and spiny endings). The anatomical diversity of nerve endings suggests that different types may convey distinct qualities of tactile experience.

The best understood of the receptors is the Merkel type, since this was the first mammalian, low-threshold mechanoreceptor to be isolated by molecular/genetic tools (Ikeda et al., 2014; Maksimovic et al., 2014; Woo et al., 2014). This is a compound structure, where a nerve terminal (Merkel neurite) abuts onto a characteristic non-neuronal, epidermal cell (Merkel cell). Transduction occurs both in the Merkel cell and Merkel neurite. Mechanical deformation of a Merkel cell triggers Piezo2-dependent membrane current and then calcium spikes. Merkel cell activity can drive activity in the neurite, probably via synaptic transmission. 


\section{Mechanical Forces Underlying Whisker Sensation}

What mechanical forces, acting on the whiskers, drive mechanotransduction in the receptors? Electrophysiological recordings from PWNs of awake, whisking animals have shown that PWNs typically are silent when the whiskers are still; fire spikes when the animal is whisking in the absence of contact ("whisking in air") and fire at a greater rate when there is whisker-object contact (Leiser \& Moxon, 2007; Khatri et al., 2009). This indicates that whisker mechanoreceptors are sensitive not only to mechanical force associated with contact but also to force associated with the whisking motion itself. In this section, we outline a mechanical framework for how mechanoreception operates in the whisker system. For more detailed review, see Campagner et al. (2018).

Biomechanical modeling has pointed to three forces that might be associated with whisking in air (Hill et al., 2008; Simony et al., 2010; Mitchinson et al., 2004; Lottem \& Azouz, 2011; Quist et al., 2014; Severson et al., 2017). First, as discussed above, the whisking rhythm is the result of coordinated contraction of intrinsic and extrinsic mystacial pad muscles. Muscle contraction squeezes pad tissue, potentially driving mechanotransduction inside the FSC. Second, like any object, a whisker and its follicle have inertia and resist being moved: the whisker-follicle unit resists being translated ("inertial force") and it resists being rotated ("inertial moment"). Third, skin is viscoelastic (Pubols, 1982). It resists both displacement ("spring force") and, like a shock absorber, it resists velocity ("damper force"). Viscosity implies that unlike an ideal spring whose length is simply proportional to applied force, skin deformation has a time-dependent character: for example, after a whisker is deflected, it takes time to return to its null position (Fraser, Hartings, \& Simons, 2006).

What are the mechanical forces associated with whisker-object contact? Since whisking occurs mainly in the horizontal plane that passes through the eyes and the nose, we restrict our attention to forces in this plane, with the caveat that out of plane forces can be significant under some circumstances (Campagner et al., 2018; Huet, Rudnicki, \& Hartmann, 2017). When an animal whisks against a static object, the object resists the whisker and exerts a (linear) reaction force $(\boldsymbol{F})$. Since mechanoreceptors are located within the whisker follicle, which rotates during whisking (Bagdasarian et al., 2013), it is useful to describe this 2D force in a follicle-centered reference frame in terms of a component parallel to the follicle ("axial force," $\boldsymbol{F}_{a x}$ ) and a component at right angles to it ("lateral force," $\boldsymbol{F}_{\text {lat }}$ ). In the same way that the weight of a diver standing at the end of a diving board causes the board to bend, the whisker-object reaction force also has a rotatory effect that causes the whisker to bend ("bending moment," $\boldsymbol{M}$ ). More precisely, bending moment can be defined around any point along the whisker shaft. Since mechanoreceptors are located in the follicle, it is bending moment at the whisker base $\left(\boldsymbol{M}_{0}\right)$ that is most relevant here.

In summary, a number of mechanical forces and moments (inertial, muscle, viscoelastic, contact, and bending) are candidates for driving mechanotransduction in the whisker fol- 
licle. In the next section, we consider how PWNs respond to sensory stimulation and how this can be understood in mechanical terms.

\section{Neural Coding in the Peripheral Whisker Sys- tem}

As the interface between world and brain, PWNs establish the basic physical signals that the brain is sensitive to. They constrain all subsequent processing at higher levels of the nervous system and play a fundamental role in whisker sensing. We therefore consider their properties in detail.

\section{Studies of Anesthetized Animals}

The standard paradigm for investigating what sensory signals a neuron encodes is to deliver precisely controlled stimuli and to measure its response. Many studies of the whisker system have used an anesthetized, passive stimulation preparation. Since whisking is suppressed by anesthesia, precise whisker deflection stimuli can be delivered using mechanical actuators. In response to ramp-and-hold whisker deflection, PWNs either respond transiently (rapidly adapting, RA) or tonically throughout the stimulus (slowly adapting, SA, Zucker \& Welker, 1969; Gibson \& Welker, 1983). Most PWNs respond preferentially to a given direction of deflection (in the plane normal to the whisker shaft, Lichtenstein, Carvell, \& Simons, 1990; Bale \& Petersen, 2009; Storchi et al., 2012). Highvelocity deflection tends to trigger particularly reliable responses (Shoykhet et al., 2000; Arabzadeh, Zorzin, \& Diamond, 2005; Bale et al., 2015). An advantage of the passive stimulation paradigm is that the experimenter can deliver almost whichever temporal pattern of whisker deflection he/she might wish to. This allows neural coding to be studied using powerful systems identification approaches, based on white noise stimuli (Rieke et al., 1999). Such studies have shown that the response of PWNs to passive whisker deflection can be accurately predicted from a weighted sum of the deflection angle and its first temporal derivative, with the relative weight varying across different PWNs in the population (Bale et al., 2013). This principle (sensitivity to deflection angle, its velocity, and direction) applies not just to PWNs but throughout the central whisker system (Pinto, Brumberg, \& Simons, 2000; Arabzadeh et al., 2003; Petersen et al., 2008, Ramirez et al., 2014), see section "Encoding of Whisking and Whisker Touch in Central Circuits"). However, what are the mechanical forces that drive responses to passive whisker deflection? Highspeed imaging (see "Box: High-Speed Imaging and Tracking") has shown that a whisker bends when it is deflected: the change in curvature is proportional to the deflection angle (Birdwell et al., 2007; Campagner et al. 2016). Similarly, the temporal derivative of the deflection angle is proportional to that of the curvature. Since whisker curvature is proportional to bending moment, this suggests that the correlations between the response of whisker neurons and deflection angle/derivative might reflect encoding of bending moment $\left(\boldsymbol{M}_{0}\right)$ and its temporal derivatives $\left(\dot{\boldsymbol{M}}_{0}\right.$, Campagner et al., 2016). Experiments 
which test whether these mechanical variables are encoded are considered later in this article.

A long-standing concern with the passive stimulation paradigm is the extent to which principles of sensory coding inferred from these conditions generalize to those of the awake, behaving animal where, as discussed previously, neuronal responses are typically generated not by passive deflection but by active whisker-object contact. A useful way to study whisker coding under an experimentally controlled approximation to active whisking conditions is by electrical whisking (Zucker \& Welker, 1969; Wallach et al., 2016). Here, whisking is elicited in anaesthetized animals by electrical stimulation of the facial nerve. Under these conditions, PWNs respond briskly to whisker-object contact, and there are several types of PWN that differ in the temporal profile of their responses (Szwed, Bagdasarian, \& Ahissar, 2003; Szwed et al., 2006). These properties are fully consistent with the mechanical framework outlined earlier in this article. Since contact involves bending, a neuron sensitive to $\boldsymbol{M}_{0}$ itself will respond throughout contact; a neuron sensitive to $\dot{\boldsymbol{M}}_{0}$ will respond at contact onset and/or offset (for a more detailed account, see Campagner et al., 2018).

\section{Studies of Awake, Behaving Animals}

The ideal way to study sensory coding, from the point of view of ethological validity, is in the awake, behaving animal. Pioneering studies of neurons in awake rats showed that PWNs are near silent in the absence of whisking and that they respond both during whisking in air, in the absence of contact, and to whisker-object contact (Leiser \& Moxon, 2007; Khatri et al., 2009). However, until recently, it was difficult to achieve mechanistic insight into the mechanical forces driving these responses and research into neural coding generally employed passive stimulation or electrical whisking paradigms. The challenge was to measure mechanical whisker forces in the behaving animal.

Due to recent technical breakthroughs, it is now possible to measure the movement and shape of whiskers in the awake, behaving mouse with high temporal resolution and from such data to estimate the mechanical forces acting on the whiskers (see "Box: HighSpeed Imaging and Tracking"). In particular, bending moment, contact force and inertial moment, or estimates of them, can be measured (Solomon \& Hartmann, 2006; Birdwell et al., 2007; Pammer et al., 2013; reviewed by Campagner et al., 2018). However, a second challenge is to dissect out contributions of different mechanical variables to neural activity in the face of correlations between these variables. Because the whisking rhythm is regular and smooth, the mechanical variables tend to correlate both in time and with one another. Classical analysis tools such as univariate regression, tuning curves, and spiketriggered averaging were designed for statistically independent variables and can generate artifactual outcomes with correlated data. For example, a neuron whose response is completely determined by variable X can appear "tuned" to variable $\mathrm{Y}$, simply as a side-effect of correlation between X and Y (Campagner et al., 2018). 


\section{Sensing the Environment With Whiskers}

To overcome the challenge of correlated data, it is important first to lower correlations by using an experimental design that, insofar as possible, decouples the relevant variables and, second, to use analysis procedures that are robust to correlation. Building on previous studies of the cortex (O'Connor et al., 2010; Huber et al., 2012; Petreanu et al., 2012; Xu et al., 2012; Peron et al., 2015), the first study to apply this approach to PWNs was by Campagner et al. (2016). They estimated whisker-related mechanical variables (whisker angle, whisker bending, axial contact force, and lateral contact force) as a mouse whisked against a metal pole. Variables were partially decoupled by varying the location of the pole. The relationship between sensory variables and PWN firing was determined by fitting generalized linear models (GLMs, Nelder \& Wedderburn, 1972). Generalizing multiple regression, GLMs seek to predict the firing rate of a given neuron as a nonlinear function of a linearly weighted sum of predictor variables and are well-suited to sensory neuroscience (Paninski, 2004; Truccolo et al., 2005; Pillow et al., 2008; Bale et al., 2013). Unless correlation is very high ("multicollinearity"), by including multiple predictors, it is possible to avoid the artifactual effects of correlation.

Using this approach, studies have investigated the forces that drive PWN activity during both whisker-object contact and whisking in air (Campagner et al., 2016; Bush et al., 2016; Severson et al., 2017). As discussed, whisker-object contact is associated with axial $\boldsymbol{F}_{a x}$ and lateral $\boldsymbol{F}_{\text {lat }}$ components of contact force as well as with bending moment around the whisker base $\left(\boldsymbol{M}_{0}\right)$. For most PWNs, the best predictors of firing rate are $\boldsymbol{M}_{0}$ and its temporal derivative $\left(\dot{\boldsymbol{M}}_{0}\right)$. For a subset of PWNs, firing rate can be predicted with increased accuracy by including axial and/or lateral force as additional predictors.

Whisking in air is associated with forces/moments due both to inertia and muscle contraction. What properties would a neuron sensitive to inertial moment be expected to have? First, since inertial moment is proportional to angular whisker acceleration, the firing rate of such a neuron should depend on acceleration. Second, since inertial moment is proportional to mass, reducing the mass of a whisker by clipping it, should reduce firing rate (at a given acceleration). Both properties have been observed in some PWNs (45\% of recorded units, Campagner et al., 2016; Severson et al., 2017). However, other whiskingsensitive PWNs are unaffected by whisker clipping, implying sensitivity to a different force. Remarkably, the firing rate of these other PWNs correlates with the temporal pattern of the electromyogram (EMG) of intrinsic or extrinsic whisker muscles, suggesting that they are predominantly sensitive to muscle force (Campagner et al., 2016; Severson et al., 2017). Collectively, these results indicate that PWN activity during whisking in air can be explained by sensitivity to a combination of inertial or muscle contraction forces.

Finally, viscoelasticity provides a simple account for the observation that PWN activity depends not only on force but also on the temporal derivative of force. The optimal weighting of these factors differs across neurons (Campagner et al., 2016; Severson et al., 2017). Modeling shows that the strain in tissue that is mechanically springlike (low viscosity) faithfully reflects the temporal profile of an applied force, whereas the strain in 
high viscosity tissue reflects the temporal derivative of the force (Mitchinson et al., 2004; Lottem \& Azouz, 2011; Severson et al., 2017).

In summary, PWN firing rate reflects forces of inertia, muscle contraction, viscoelasticity, contact, and bending, with the relative weighting of these terms differing across neurons. At the population level, therefore, a heterogeneous PWN population encodes a multidimensional "force space." This implies that to accurately decode mechanical events at a whisker, central neural circuits may need to integrate signals across different PWN types.

\section{Role of Different Mechanoreceptor Types}

A long-standing question has been how the function of a PWN (which tactile variables it is tuned to) corresponds to the morphological structure of its nerve endings in the FSC. There have been two important recent breakthroughs. First, intra-axonal recording and labeling in vivo has allowed the peripheral nerve ending of a PWN to be identified and correlated with tactile responses (Tonomura et al., 2015). Second, protein markers have been discovered which are expressed selectively among the different nerve endings (Lima et al., 2009; Takatoh et al., 2017). This enables an "optical tagging" strategy, by means of which individual classes of nerve ending can be labeled with an opsin reporter and then identified by light stimulation.

Mouse lines have recently been developed that specifically label Merkel cells and have been used to illuminate the properties of Merkel cells, located both in touch domes of hairy skin and in whisker follicles (Maksimovic et al., 2014; Ikeda et al., 2014; Bai et al., 2015). Severson et al. (2017) used optical tagging to study Merkel-associated SA PWNs and showed that Merkel-associated afferents responded similarly to other unidentified SA afferents in encoding combinations of $\boldsymbol{M}_{0}, \dot{\boldsymbol{M}}_{0}$ and whisking-associated forces (for inertial and muscle forces, see section "Mechanical Forces Underlying Whisker Sensation"). Using intra-axonal recording and labeling, Tonomura et al. (2015) isolated nerve endings of different types and found that clublike endings were the type most sensitive to air puff stimulation of the whiskers. Future optogenetic tagging (Severson et al., 2017), intra-axonal labelling (Tonomura et al., 2015) or cell-type specific imaging studies (Ghitani et al., 2017) that isolate other mechanoreceptor types will be needed to determine the full picture of how the various nerve endings in the FSC-Merkel, lanceolate, clublike, and spiny -encode whisker-related forces.

\section{Neural Coding in the Central Whisker System}

In this section, we consider how the information that PWNs provide about whisker-object contact and whisking movement is propagated and transformed along the ascending pathway. 


\section{Coding of Whisker Forces in the Thalamocortical Pathway}

PWNs are typically tuned to whisking phase. That is, a PWN fires at a greater rate during a particular part of the whisking cycle (Khatri et al., 2009; Campagner et al., 2016; Wallach et al., 2016; Severson et al., 2017). Phase tuning is common both at brainstem and thalamic levels of the pathway (Moore et al., 2015; Urbain et al., 2015; J. Yu et al., 2016; Wallach et al., 2016). In awake, behaving animals, neurons in the lemniscal pathway (PrV and VPM) are, on average, more strongly tuned to whisking phase than those in the paralemniscal pathway (SpVi and POM). The touch-selectivity of PWNs is also reliably propagated along the ascending pathway. At the level of thalamus, VPM neurons respond to touch both during electrical whisking (Yu et al., 2006) and in awake animals (Yu et al., 2016). Thus, the thalamocortical terminals that synapse in S1 convey reliable information about both whisking phase and whisker-object touch.

Within S1, however, there are important transformations. Thalamo-cortical transformation has mainly been studied in anesthetized animals: in comparison to VPM, S1 neurons tend to respond in a more complex manner (nonlinear, adaptive, multidimensional, as reviewed by Bale \& Maravall, 2018). Although much likely remains to be discovered about such transformations in the behaving animal, two points are clear. First, as detailed in the following section, it is mainly at the level of S1 that neurons first become sensitive to behavioral choice. Second, excitatory neurons in layer 4 are much more strongly driven by touch than by whisking alone (Hires et al., 2015; Yu et al., 2016). This transformation can be understood as a consequence of the concept that layer 4 circuitry is tuned to synchronous thalamic input (Bruno \& Sakmann, 2006; Pinto et al., 2003). This phenomenon arises due to a feedforward inhibition circuit whereby VPM input drives both excitatory and inhibitory neurons within an S1 barrel (Gutnisky et al., 2017; Yu et al., 2016). If VPM spiking is temporally diffuse, as is the case during whisking in air (since different neurons have different preferred phases), fast and potent inhibition attenuates the firing of excitatory neurons. If, in contrast, VPM spiking is synchronous on a millisecond time scale, as is the case at the onset of whisker-object contact, the layer 4 excitatory neurons have a brief window of opportunity to fire before the inhibitory gate is closed. The function of this circuit may be to disambiguate the cortical response so that spikes of individual neurons more closely reflect touch events. Note, however, that whisking phase is encoded in the residual response to whisking (Curtis \& Kleinfeld, 2009; Hires et al., 2015). Although relatively weak at the level of individual neurons, whisker phase can be accurately decoded from population activity in both S1 and M1 (Hill et al., 2011; Peron et al., 2015).

Since whisker-object contact causes whisker bending, these results indicate that tuning to bending moment $\boldsymbol{M}_{0}$ is widespread throughout the ascending pathway. Direct evidence for this is that the firing rate (or, in some studies, calcium reporter fluorescence) of neurons in both S1 and M1 depends on whisker curvature (Chen et al., 2013; Hires et al., 2015; Huber et al., 2012; O'Connor et al., 2010; O'Connor et al., 2013; Peron et al., 2015; Petreanu et al., 2012; Xu et al., 2012; Yu et al., 2016). Whether, as in PWNs, neuronal firing rate depends on $\boldsymbol{M}_{0}$ itself and/or its temporal derivative $\dot{\boldsymbol{M}}_{0}$ has not been studied directly in cortex. However, there is considerable indirect evidence that, as in PWNs, $\dot{\boldsymbol{M}}_{0}$ is 
robustly encoded. First, many neurons in VPM/S1 fire phasically to touch onset (when $\dot{\boldsymbol{M}}_{0}$ is high) rather than throughout touch (Gutnisky et al., 2017; Hires et al., 2015; Yu et al., 2016). Second, studies of passive whisker deflection have consistently shown robust encoding of deflection velocity (Arabzadeh et al., 2003; Montemurro et al., 2007; Petersen et al., 2008; Pinto et al., 2000). As previously discussed, this suggests encoding of $\dot{\boldsymbol{M}}_{0}$. Third, when rats/mice whisk against textured surfaces, the whiskers have a tendency to move in a jerky fashion, as they first stick against the surface before slipping over it (stick-slip movements; Isett, Feasal, Lane, \& Feldman, 2018; Jadhav et al., 2009; Wolfe et al., 2008). These high-velocity slips evoke cortical firing and likely correspond to times of high $\dot{\boldsymbol{M}}_{0}$.

In sum, neurons throughout the whisker system encode mechanical forces associated with the whisking rhythm itself and with whisker-object contact. This mechanical framework provides a concise account of extensive experimental observations from both awake behaving, electrical whisking, and passive stimulation paradigms. The basic feature of selectivity is established by first-order neurons (PWNs). Sensitivity to whisker-object contact force is reliably propagated across the ascending pathway to S1/M1. In contrast, sensitivity to whisking forces is substantially attenuated. This attenuation may reflect a solution to a general computational problem that applies also to vision (Rushton \& Warren, 2005)—compensation for self-motion.

\section{Role of Association Cortex}

What of "association cortex" - the areas of the cerebral cortex that are neither primary sensory nor primary motor? Investigation of association cortex in whisker-dependent behavior is in its infancy but is valuable due to the powerful methods that can be brought to bear using this model system. Recent studies illuminate one of the central concerns of cognitive neuroscience: how sensory signals are translated into choices.

Translation of sensory signals into choice can be studied by recording neural activity during perceptual tasks where animals are trained to make choices depending on a sensory stimulus (Britten et al., 1996). In whisker versions of such tasks, mice have been trained to detect deflection of a whisker and to discriminate the location/texture of an object (Chen et al., 2013; Kwon et al., 2016; Yang et al., 2016). Use of mice has permitted new molecular genetic tools to be applied, allowing the role of specific corticocortical pathways to be teased apart. Whereas neural activity correlates with sensory signals throughout the whisker system, prolonged neural activity that correlates with choice first emerges at the level of S1 (Yang, Kwon, Severson, \& O’Connor, 2016). S1 is reciprocally connected with S2 and M1, and these areas are at least partially specialized for different tasks. S1 neurons that project to M1 discriminate the location of an object better than its texture; S1 neurons that project to S2 discriminate texture better than location (Chen et al., 2013). In S2, the choice-related signal is stronger relative to the stimulus signal than it is in S1, suggesting a shift in coding from strictly sensory to choice (Kwon, Yang, Minamisawa, \& O'Connor, 2016). However, the computation is unlikely to be simply feedforward, since a strong choice-related signal is present both in the feedback projection from 


\section{Sensing the Environment With Whiskers}

S2 to S1 and in the specific subpopulation of neurons in S1 layers 2 and 3 that project to S2 (Kwon et al., 2016). This suggests that computation of choice involves a distributed network involving both S1 and S2, and characterized by multi-area dynamics.

The neural basis of behavioral choices that depend on short-term memory can be studied with delayed response tasks (Furster \& Alexander, 1971). Recently, whisker-guided versions have been introduced (Guo et al., 2014; Guo et al., 2017; Li et al., 2015). Here, mice whisk against a pole (sample period) then wait for 1 to 2 s (delay period) until an auditory cue signals that they can lick to report their decision (response period). In S1, neuronal activity discriminates pole location mainly during the sample period and inactivation impairs performance much more during the sample period than during the delay period (Guo et al., 2014). In contrast, in a region of premotor cortex called ALM (anterior lateral motor cortex, Guo et al., 2014), neuronal activity exhibits robust, persistent activity during the delay/response periods that discriminates pole location, and inactivation impairs performance more during the delay than the sample period (Guo et al., 2014). These data suggest a contrast between primary and association areas: S1 is involved with instantaneous sensory processing; ALM with short-term memory. The persistent ALM activity is neither simply relayed to ALM from elsewhere nor generated purely within ALM itself (Li et al., 2016). Rather, the persistent activity appears to reflect dynamics of a multi-area network, encompassing both ALM and motor thalamus (ventral medial and ventral anterior lateral nuclei, Guo et al., 2017).

\section{Using Mechanical Cues to Guide Tactile Behavior}

The robust encoding of bending moment throughout the whisker system suggests that this signal provides useful information for understanding the world through whisker sensing. How this might work is not known but computational/robotic work offers valuable clues. Since whiskers bend upon contact $\boldsymbol{M}_{0}$ (and, especially, $\dot{\boldsymbol{M}}_{0}$ ) is a cue to touch. Being conical, a whisker is stiff at the base and becomes increasingly bendy toward the tip. Thus, $\boldsymbol{M}_{0}$ tends to be higher for contact near the whisker base than for contact near the tip; this is reflected in PWN firing rate (Szwed et al., 2006). In this way, $\boldsymbol{M}_{0}$ is a cue to the radial location of a contact. However, since $\boldsymbol{M}_{0}$ is also influenced by contact strength, more reliable information about radial contact location can be obtained by normalizing $\boldsymbol{M}_{0}$ with respect to axial/lateral contact force (Pammer et al., 2013; Bagdasarian et al., 2013). Robot studies have showed that $\boldsymbol{M}_{0}$ sensing can, in principle, allow the shape of an object or the contours of an environment to be inferred by integrating across touches (Kaneko, 1994; Solomon \& Hartmann, 2006; Fox et al., 2012).

An important behavioral use of whiskers is to discriminate objects by their texture. As noted above, whisker-object interactions involve stick-slip events that are likely to be associated with rapid changes in bending moment. The temporal pattern of these events can differ depending on the surface texture (Arabzadeh et al., 2005; Jadhav et al., 2009) and is, therefore, a cue that animals may use for perceiving the edges and textures of surfaces (Chen et al., 2013; Hipp et al., 2006; Isett et al., 2018; McGuire et al., 2016).

Smooth and coarse textures differ in the firing rate that they evoke (von Heimendahl et

Page 21 of 39

PRINTED FROM the OXFORD RESEARCH ENCYCLOPEDIA, NEUROSCIENCE (oxfordre.com/neuroscience). (c) Oxford University Press USA, 2020. All Rights Reserved. Personal use only; commercial use is strictly prohibited (for details see Privacy Policy and Legal Notice). 
al., 2007); more similar textures can evoke similar firing rates but still be discriminable through differences in the temporal patterning of the spikes (Arabzadeh et al., 2006).

\title{
Coding by Spike Timing
}

Whisking against textured surfaces illustrates that neurons can convey information not simply by the number of spikes that they fire but also by the precise temporal distribution of those spikes (Rieke et al., 1999; Petersen et al., 2009). Coding by spike timing is potentially important since it vastly increases the potential bandwidth of neurons to convey information (MacKay \& McCulloch, 1952; Petersen, 2013). However, for this coding mechanism to be used by the brain, a number of conditions must be met. First, neurons must be able to fire spikes that are timed with high precision. This can be quantified by trial-to-trial variability in the post-stimulus time at which a spike occurs (jitter). One way in which the whisker system is remarkable is that PWNs can respond to high-velocity whisker deflection with a jitter on the order of 10s of microseconds (Bale et al., 2015), ranking PWNs as among the most reliable (and hence most informative) sensory neurons in nature. Second, high temporal precision responses must be reliably propagated along neural pathways to decision-making circuits. Exactly comparable experiments to that of Bale et al. (2015) have not been performed at higher levels of the whisker system, but sub-millisecond jitter has been demonstrated in the lemniscal pathway, both in VPm thalamus and layer 4 of S1 (Hires et al., 2015; Montemurro et al., 2007). Third, neurons must convey more information by the temporal pattern of spikes than by the number of spikes alone (Panzeri et al., 2001; Petersen et al., 2001; Petersen et al., 2002; Panzeri et al., 2003; Panzeri et al., 2007). This condition can be tested using Shannon's concept of Mutual Information (Shannon, 1948): in the whisker system, such studies have shown that neurons convey potentially useful information by precise spike timing (reviewed by Petersen et al., 2009). Finally, information conveyed by spike timing must not only be present in neural activity, it must be used to influence behavior. This has been difficult to study directly, but the innovative study Zuo et al. (2015) showed that a rat's choice in a texture discrimination task could be more accurately predicted from S1 spike trains by a decoder based on spike timing than a decoder based only on spike count. In sum, like audition, whisker sensing is characterized by neural signals with high temporal bandwidth: coding by precise spike timing plays an important role in neural communication.

\section{Conclusion: The Past and Future Role of Barrel Cortex at the Frontiers of Neuroscience}

\begin{abstract}
Whiskers are, primarily, sensors of bending moment (and changes of it). Neurons throughout the whisker-related parts of the brain robustly encode this quantity, suggesting that it is fundamental to guiding their behavior. By tuning parameters of whisking control parameters (notably amplitude and setpoint) according to their current behavioral goals, whisking animals are able to use the information provided by their whisker sensors to solve an impressive variety of behavioral tasks.
\end{abstract}


Finally, we return to the point that originally motivated the explosion of work on the whisker system-its modular architecture. The hallmark of the system is the discrete neural modules-barrels, barreloids, and barrelettes-associated with each whisker. Although it has long been thought that the collective activity of many neurons $(\sim 10,000$ in the case of a barrel column) is key to neural computation (Mountcastle, 1997), until recently, it was not possible to record from more than a handful of neurons simultaneously.

The whisker system has been a key test-bed both for the development of population recording via in vivo calcium imaging (O'Connor et al., 2010; Stosiek et al., 2003) and for that of optogenetic control of the activity of cortical neurons (Huber et al., 2008; O'Connor et al., 2013). In a remarkable tour de force, Peron et al. (2015) recorded from $\sim 80 \%$ of the neurons in the layer 2 to 3 part of a barrel column during a pole localization task and thereby revealed the spatial coding of touch and whisking related signals with exquisite resolution. Application and further development of such methods is likely to put the whisker system at the forefront of progress in systems neuroscience for years to come.

\section{Further Reading}

Campagner, D., Evans, M. H., Loft, M. S., \& Petersen, R. S. (2018). What the whiskers tell the brain. Neuroscience, 368, 95-108.

Moore, J. D., Kleinfeld, D., \& Wang, F. (2014). How the brainstem controls orofacial behaviors comprised of rhythmic actions. Trends in Neurosciences, 37(7), 370-380.

O'Connor, D. H., Huber, D., \& Svoboda, K. (2009). Reverse engineering the mouse brain. Nature, 461(7266), 923.

\section{References}

Agmon, A., \& Connors, B. W. (1991). Thalamocortical responses of mouse somatosensory (barrel) cortex in vitro. Neuroscience, 41(2), 365-379.

Ahl, A. S. (1982). Evidence of use of vibrissae in swimming in Sigmo don fulviventer. Animal Behaviour, 30(4), 1203-1206.

Alloway, K. D., Smith, J. B., Mowery, T. M., \& Watson, G. D. (2017). Sensory processing in the dorsolateral striatum: the contribution of thalamostriatal pathways. Frontiers in systems neuroscience, $11,53$.

Arabzadeh, E., Panzeri, S., \& Diamond, M. E. (2006). Deciphering the spike train of a sensory neuron: Counts and temporal patterns in the rat whisker pathway. The Journal of Neuroscience, 26(36), 9216-9226.

Arabzadeh, E., Petersen, R. S., \& Diamond, M. E. (2003). Encoding of whisker vibration by rat barrel cortex neurons: Implications for texture discrimination. The Journal of Neuroscience, 23(27), 9146-9154. 
Arabzadeh, E., Zorzin, E., \& Diamond, M. E. (2005). Neuronal encoding of texture in the whisker sensory pathway. PLoS Biology, 3(1), e17.

Arkley, K., Grant, R. A., Mitchinson, B., \& Prescott, T. J. (2014). Strategy change in vibrissal active sensing during rat locomotion. Current Biology, 24(13), 1507-1512.

Ashby, K. R. (1972). Patterns of daily activity in mammals. Mammal Review, 1(7-8), 171185.

Bagdasarian, K., Szwed, M., Knutsen, P. M., Deutsch, D., Derdikman, D., Pietr, M., Simony, E., \& Ahissar, E. (2013). Pre-neuronal morphological processing of object location by individual whiskers. Nature neuroscience, 16(5), 622-631.

Bai, L., Lehnert, B. P., Liu, J., Neubarth, N. L., Dickendesher, T. L., Nwe, P. H., Cassidy, C., Woodbury, C. J., \& Ginty, D. D. (2015). Genetic identification of an expansive mechanoreceptor sensitive to skin stroking. Cell, 163(7), 1783-1795.

Bale, M. R., Davies, K., Freeman, O. J., Ince, R. A., \& Petersen, R. S. (2013). Low-dimensional sensory feature representation by trigeminal primary afferents. Journal of Neuroscience, 33(29), 12003-12012.

Bale, M. R., Campagner, D., Erskine, A., \& Petersen, R. S. (2015). Microsecond-scale timing precision in rodent trigeminal primary afferents. Journal of Neuroscience, 35(15), 5935-5940.

Bale, M. R., \& Petersen, R. S. (2009). Transformation in the neural code for whisker deflection direction along the lemniscal pathway. Journal of Neurophysiology, 102(5), 27712780.

Bale, M. R., \& Maravall, M. (2018). Organization of sensory feature selectivity in the whisker system. Neuroscience, 368, 70-80.

Beddard, F. E. (1902). Observations upon the carpal vibrissae in mammals. Journal of Zoology.

Berg, R. W., \& Kleinfeld, D. (2003). Rhythmic whisking by rat: Retraction as well as protraction of the vibrissae is under active muscular control. Journal of Neurophysiology, 89(1), 104-117.

Bermejo, R., Houben, D., \& Zeigler, H. P. (1998). Optoelectronic monitoring of individual whisker movements in rats. Journal of Neuroscience Methods, 83(2), 89-96.

Bermejo, R., Vyas, A., \& Zeigler, H. P. (2002). Topography of rodent whisking-I. Two-dimensional monitoring of whisker movements. Somatosensory \& Motor Research, 19(4), 341-346. 
Birdwell, J. A., Solomon, J. H., Thajchayapong, M., Taylor, M. A., Cheely, M., Towal, R. B., Conradt, J., \& Hartmann, M. J. (2007). Biomechanical models for radial distance determination by the rat vibrissal system. Journal of Neurophysiology, 98(4), 2439.

Bosman, L. W., Houweling, A. R., Owens, C. B., Tanke, N., Shevchouk, O. T., Rahmati, N., Teunissen, W. H., Ju, C., Gong, W., Koekkoek, S. K., \& De Zeeuw, C. I. (2011). Anatomical pathways involved in generating and sensing rhythmic whisker movements. Frontiers in Integrative Neuroscience, 5, 53.

Brecht, M., Schneider, M., Sakmann, B., \& Margrie, T. W. (2004). Whisker movements evoked by stimulation of single pyramidal cells in rat motor cortex. Nature, 427(6976), 704-710.

Brecht, M., Preilowski, B., \& Merzenich, M. M. (1997). Functional architecture of the mystacial vibrissae. Behavioural Brain Research, 84(1-2), 81-97.

Britten, K. H., Newsome, W. T., Shadlen, M. N., Celebrini, S., \& Movshon, J. A. (1996). A relationship between behavioral choice and the visual responses of neurons in macaque MT. Visual Neuroscience, 13, 87-100.

Broughton, S. D. (1823). On the use of the whiskers in feline and other animals. London Medical Physics Journal, 49, 397-398.

Bruno, R. M., \& Sakmann, B. (2006). Cortex is driven by weak but synchronously active thalamocortical synapses. Science, 312(5780), 1622-1627.

Bush, N. E., Schroeder, C. L., Hobbs, J. A., Yang, A. E., Huet, L. A., Solla, S. A., \& Hartmann, M. J. (2016). Decoupling kinematics and mechanics reveals coding properties of trigeminal ganglion neurons in the rat vibrissal system. Elife, 5, e13969.

Campagner, D., Evans, M. H., Bale, M. R., Erskine, A., \& Petersen, R. S. (2016). Prediction of primary somatosensory neuron activity during active tactile exploration. Elife, 5, e10696.

Campagner, D., Evans, M. H., Loft, M. S. E., \& Petersen, R. S. (2017). What the whiskers tell the brain. Neuroscience.

Campagner, D., Evans M. H. et al. (2017). Mechanosensory basis of active tactile discrimination. Manuscript in Preparation.

Campagner, D., Evans, M. H., Chlebikova, K., Colins-Rodriguez, A., Loft, M. S. E., Fox, S., Pettifer, D., Humphries, M. D., Svoboda, K., \& Petersen, R. S. (2019). Prediction of choice from competing mechanosensory and choice-memory cues during active tactile decision making. Journal of Neuroscience, 2217-2218.

Campi, K. L., \& Krubitzer, L. (2010). Comparative studies of diurnal and nocturnal rodents: Differences in lifestyle result in alterations in cortical field size and number. The Journal of Comparative Neurology, 518(22), 4491-4512. 
Carvell, G. E., \& Simons, D. J. (1990). Biometric analyses of vibrissal tactile discrimination in the rat. The Journal of Neuroscience, 10(8), 2638-2648.

Carvell, G. E., \& Simons, D. J. (1995). Task- and subject-related differences in sensorimotor behavior during active touch. Somatosensory \& Motor Research, 12(1), 1-9.

Cases, O., Vitalis, T., Seif, I., De Maeyer, E., Sotelo, C., \& Gaspar, P. (1996). Lack of barrels in the somatosensory cortex of monoamine oxidase A-deficient mice: role of a serotonin excess during the critical period. Neuron, 16(2), 297-307.

Catania, K.C. (2002). Barrels, stripes, and fingerprints in the brain-implications for theories of cortical organization. Journal of Neurocytology, 31(3), 347-358.

Chen, J. L., Carta, S., Soldado-Magraner, J., Schneider, B. L., \& Helmchen, F. (2013). Behaviour-dependent recruitment of long-range projection neurons in somatosensory cortex. Nature, 499(7458), 336-340.

Chorev, E., Preston-Ferrer, P., \& Brecht, M. (2016). Representation of egomotion in rat's trident and E-row whisker cortices. Nature Neuroscience.

Clack, N. G., O'Connor, D. H., Huber, D., Petreanu, L., Hires, A., Peron, S., Svoboda, K., \& Myers, E. W. (2012). Automated tracking of whiskers in videos of head fixed rodents.

PLoS Computational Biology, 8(7), e1002591.

Corey, D. P., \& Hudspeth, A. J. (1979). Response latency of vertebrate hair cells. Biophysical Journal, 26(3), 499-506.

Coste, B., Mathur, J., Schmidt, M., Earley, T. J., Ranade, S., Petrus, M. J., Dubin, A. E., \& Patapoutian, A. (2010). Piezo1 and Piezo2 are essential components of distinct mechanically activated cation channels. Science, 330(6000), 55-60.

Curtis, J. C., \& Kleinfeld, D. (2009). Phase-to-rate transformations encode touch in cortical neurons of a scanning sensorimotor system. Nature Neuroscience, 12(4), 492-501.

Darwin, C. R. (1871). The descent of man, and selection in relation to sex (Vol. 1, 1st Ed.). London: John Murray.

Darwin, C. (1888). The descent of man and selection in relation to sex, Murray.

Dehnhardt, G. et al. (2001). Hydrodynamic trail-following in harbor seals (Phoca vitulina). Science, 293(5527), 102-104.

Dehnhardt, G., Mauck, B., \& Bleckmann, H. (1998). Seal whiskers detect water movements. Nature, 394(6690), 235.

Deschênes, M., Takatoh, J., Kurnikova, A., Moore, J. D., Demers, M., Elbaz, M., Furuta, T., Wang, F., \& Kleinfeld, D. (2016). Inhibition, not excitation, drives rhythmic whisking. Neuron, 90(2), 374-387. 
Diamond, M. E., \& Arabzadeh, E. (2013). Whisker sensory system-from receptor to decision. Progress in Neurobiology, 103, 28-40.

Dörfl, J. (1985). The innervation of the mystacial region of the white mouse: A topographical study. Journal of Anatomy, 142, 173-184.

Ebara, S., Kumamoto, K., Matsuura, T., Mazurkiewicz, J. E., \& Rice, F. L. (2002). Similarities and differences in the innervation of mystacial vibrissal follicle-sinus complexes in the rat and cat: a confocal microscopic study. Journal of Comparative Neurology, 449(2), 103-119.

Erzurumlu, R. S., \& Gaspar, P. (2012). Development and critical period plasticity of the barrel cortex. The European Journal of Neuroscience, 35(10), 1540-1553.

Fassihi, A., Akrami, A., Esmaeili, V., \& Diamond, M. E. (2014). Tactile perception and working memory in rats and humans. Proceedings of the National Academy of Sciences, 111(6), 2331-2336.

Favaro, P. D. N., Gouvêa, T. S., De Oliveira, S. R., Vautrelle, N., Redgrave, P., \& Comoli, E. (2011). The influence of vibrissal somatosensory processing in rat superior colliculus on prey capture. Neuroscience, 176, 318-327.

Fee, M. S., Mitra, P. P., \& Kleinfeld, D. (1997). Central versus peripheral determinants of patterned spike activity in rat vibrissa cortex during whisking. Journal of Neurophysiology, 78(2), 1144-1149.

Feldman, D. E., \& Brecht, M. (2005). Map plasticity in somatosensory cortex. Science, 310(5749), 810-815.

Feldmeyer, D., Brecht, M., Helmchen, F., Petersen, C. C., Poulet, J. F., Staiger, J. F., Luhmann, H. J., \& Schwarz, C. (2013). Barrel cortex function. Progress in neurobiology, 103, $3-27$.

Fox, C., Evans, M., Pearson, M., \& Prescott, T. (2012). Tactile SLAM with a biomimetic whiskered robot. In 2012 IEEE International Conference on Robotics and Automation (pp. 4925-4930). IEEE.

Fox, K. (1992). A critical period for experience-dependent synaptic plasticity in rat barrel cortex. The Journal of Neuroscience, 12(5), 1826-1838.

Fraser, G., Hartings, J. A., \& Simons, D. J. (2006). Adaptation of trigeminal ganglion cells to periodic whisker deflections. Somatosensory \& Motor Research, 23(3-4), 111-118.

Fuster, J. M., \& Alexander, G. E. (1971). Neuron activity related to short-term memory. Science, 173(3997), 652-654. 
Gao, P., Hattox, A. M., Jones, L. M., Keller, A., \& Zeigler, H. P. (2003). Whisker motor cortex ablation and whisker movement patterns. Somatosensory \& Motor Research, 20(3-4), 191-198.

Gao, P., Bermejo, R., \& Zeigler, H. P. (2001). Whisker deafferentation and rodent whisking patterns: Behavioral evidence for a central pattern generator. The Journal of Neuroscience, 21(14), 5374-5380.

Ghitani, N., Barik, A., Szczot, M., Thompson, J. H., Li, C., Le Pichon, C. E., Krashes, M. J., $\&$ Chesler, A. T. (2017). Specialized mechanosensory nociceptors mediating rapid responses to hair pull. Neuron, 95(4), 944-954.

Gibson, J. J. (1962). Observations on active touch. Psychological Review, 69, 477-491.

Gibson, J. M., \& Welker, W. I. (1983). Quantitative studies of stimulus coding in first-order vibrissa afferents of rats. 1. Receptive field properties and threshold distributions. Somatosensory Research, 1(1), 51-67.

Gläser, N., Wieskotten, S., Otter, C., Dehnhardt, G., \& Hanke, W. (2011). Hydrodynamic trail following in a California sea lion (Zalophus californianus). Journal of Comparative Physiology A, 197(2), 141-151.

Grant, R., Wieskotten, S., Wengst, N., Prescott, T., \& Dehnhardt, G. (2013). Vibrissal touch sensing in the harbor seal (Phoca vitulina): how do seals judge size? Journal of Comparative Physiology A, 199(6), 521-533.

Grant, R. A., Mitchinson, B., Fox, C. W., \& Prescott, T. J. (2009). Active touch sensing in the rat: Anticipatory and regulatory control of whisker movements during surface exploration. Journal of Neurophysiology, 101(2), 862-874.

Grinevich, V., Brecht, M., \& Osten, P. (2005). Monosynaptic pathway from rat vibrissa motor cortex to facial motor neurons revealed by lentivirus-based axonal tracing. The Journal of Neuroscience, 25(36), 8250-8258.

Guić-Robles, E., Valdivieso, C., \& Guajardo, G. (1989). Rats can learn a roughness discrimination using only their vibrissal system. Behavioural Brain Research, 31 (3), 285-289.

Guic-Robles, E., Jenkins, W. M., \& Bravo, H. (1992). Vibrissal roughness discrimination is barrel cortex-dependent. Behavioural Brain Research, 48(2), 145-152.

Guo, Z. V., Li, N., Huber, D., Ophir, E., Gutnisky, D., Ting, J.T., . . Svoboda, K. (2014). Flow of cortical activity underlying a tactile decision in mice. Neuron, 81(1), 179-194.

Guo, Z. V., Inagaki, H. K., Daie, K., Druckmann, S., Gerfen, C. R. \& Svoboda, K. (2017). Maintenance of persistent activity in a frontal thalamocortical loop. Nature, 545(7653), 181-186. 
Gutnisky, D. A., Yu, J., Hires, S. A., To, M. S., Bale, M., Svoboda, K., \& Golomb, D. (2017). Mechanisms underlying a thalamocortical transformation during active tactile sensation. PLoS Computational Biology, 13(6), e1005576.

Haidarliu, S. (2015). Whisking musculature. Scholarpedia Journal, 10(4), 32331.

Hall, R. D., \& Lindholm, E. P. (1974). Organization of motor and somatosensory neocortex in the albino rat. Brain Research, 66(1), 23-38.

Hanke, W., Witte, M., Miersch, L., Brede, M., Oeffner, J., Michael, M., . . Dehnhardt, G., 2010. Harbor seal vibrissa morphology suppresses vortex-induced vibrations. Journal of Experimental Biology, 213(15), 2665-2672.

Harris, J. A., Petersen, R. S., \& Diamond, M. E. (1999). Distribution of tactile learning and its neural basis. Proceedings of the National Academy of Sciences of the United States of America, 96(13), 7587-7591.

Hattox, A. M., Priest, C. A., \& Keller, A. (2002). Functional circuitry involved in the regulation of whisker movements. The Journal of Comparative Neurology, 442(3), 266-276.

Von Heimendahl, M., Itskov, P. M., Arabzadeh, E., \& Diamond, M. E. (2007). Neuronal activity in rat barrel cortex underlying texture discrimination. PLoS Biology, 5(11), e305.

Hill, D. N., Bermejo, R., Zeigler, H. P., \& Kleinfeld, D. (2008). Biomechanics of the vibrissa motor plant in rat: rhythmic whisking consists of triphasic neuromuscular activity. Journal of Neuroscience, 28(13), 3438-3455.

Hill, D. N., Curtis, J. C., Moore, J. D., \& Kleinfeld, D. (2011). Primary motor cortex reports efferent control of vibrissa motion on multiple timescales. Neuron, 72(2), 344-356.

Hipp, J., Arabzadeh, E., Zorzin, E., Conradt, J., Kayser, C., Diamond, M. E., \& Konig, P. (2006). Texture signals in whisker vibrations. Journal of Neurophysiology, 95(3), 17921799.

Hires, S. A., Gutnisky, D. A., Yu, J., O'Connor, D. H., \& Svoboda, K. (2015). Low-noise encoding of active touch by layer 4 in the somatosensory cortex. Elife, 4, e06619.

Houweling, A. R., \& Brecht, M. (2008). Behavioural report of single neuron stimulation in somatosensory cortex. Nature, 451(7174), 65-68.

Huber, D., Gutnisky, D. A., Peron, S., O’Connor, D. H., Wiegert, J. S., Tian, L., Oertner, T. G., Looger, L. L., \& Svoboda, K. (2012). Multiple dynamic representations in the motor cortex during sensorimotor learning. Nature, 484(7395), 473-478.

Huber, D., Petreanu, L., Ghitani, N., Ranade, S., Hromádka, T., Mainen, Z., \& Svoboda, K. (2008). Sparse optical microstimulation in barrel cortex drives learned behaviour in freely moving mice. Nature, 451(7174), 61-64. 


\section{Sensing the Environment With Whiskers}

Huet, L.A., Rudnicki, J. W., \& Hartmann, M. J. Z. (2017). Tactile sensing with whiskers of various shapes: Determining the three-dimensional location of object contact based on mechanical signals at the whisker base. Soft Robotics, 4(2), 88-102.

Hutson, K. A., \& Masterton, R. B. (1986). The sensory contribution of a single vibrissa's cortical barrel. Journal of Neurophysiology, 56(4), 1196-1223.

Isett, B. R., Feasel, S. H., Lane, M. A., \& Feldman, D. E. (2018). Slip-based coding of local shape and texture in mouse S1. Neuron, 97(2), 418-433.

Ikeda, R., Cha, M., Ling, J., Jia, Z., Coyle, D., \& Gu, J. G. (2014). Merkel cells transduce and encode tactile stimuli to drive $A \beta$-afferent impulses. Cell, 157(3), 664-675.

Jadhav, S. P., Wolfe, J., \& Feldman, D. E. (2009). Sparse temporal coding of elementary tactile features during active whisker sensation. Nature Neuroscience, 12(6), 792-800.

Kaneko, M. (1994). Active antenna. In Proceedings of the 1994 IEEE International Conference on Robotics and Automation (pp. 2665-2671). IEEE.

Khatri, V., Bermejo, R., Brumberg, J. C., Keller, A., \& Zeigler, H. P. (2009). Whisking in air: encoding of kinematics by trigeminal ganglion neurons in awake rats. Journal of Neurophysiology, 101(4), 1836-1846.

Klein, B. G., \& Rhoades, R. W. (1985). Representation of whisker follicle intrinsic musculature in the facial motor nucleus of the rat. The Journal of Comparative Neurology, 232(1), 55-69.

Kleinfeld, D., Ahissar, E., \& Diamond, M. E. (2006). Active sensation: Insights from the rodent vibrissa sensorimotor system. Current Opinion in Neurobiology, 16(4), 435-444.

Kleinfeld, D., Berg, R. W., \& O’Connor, S. M. (1999). Invited review: Anatomical loops and their electrical dynamics in relation to whisking by rat. Somatosensory \& Motor Research, 16(2), 69-88.

Knutsen, P. M., Biess, A., \& Ahissar, E. (2008). Vibrissal kinematics in 3D: Tight coupling of azimuth, elevation, and torsion across different whisking modes. Neuron, 59(1), 35-42.

Knutsen, P. M., Derdikman, D., \& Ahissar, E. (2005). Tracking whisker and head movements in unrestrained behaving rodents. Journal of Neurophysiology, 93(4), 2294-2301.

Knutsen, P. M., Pietr, M., \& Ahissar, E. (2006). Haptic object localization in the vibrissal system: Behavior and performance. The Journal of Neuroscience, 26(33), 8451-8464.

Krubitzer, L., Campi, K. L., \& Cooke, D. F. (2011). All rodents are not the same: A modern synthesis of cortical organization. Brain, Behavior and Evolution, 78(1), 51-93.

Krupa, D. J., Matell, M. S., Brisben, A. J., Oliveira, L. M., \& Nicolelis, M. A. (2001). Behavioral properties of the trigeminal somatosensory system in rats performing whisker-dependent tactile discriminations. Journal of Neuroscience, 21(15), 5752-5763. 
Kwon, S. E., Yang, H., Minamisawa, G., \& O’Connor, D. H. (2016). Sensory and decisionrelated activity propagate in a cortical feedback loop during touch perception. Nature Neuroscience, 19(9), 1243-1249.

Kyriazi, H. T., \& Simons, D. J. (1993). Thalamocortical response transformations in simulated whisker barrels. Social Neuroscience, 13(4), 1601-1615.

Lederman, S. J., \& Klatzky, R. L. (1987). Hand movements: A window into haptic object recognition. Cognitive Psychology, 19(3), 342-368.

Lee, K. J., \& Woolsey, T. A. (1975). A proportional relationship between peripheral innervation density and cortical neuron number in the somatosensory system of the mouse. Brain Research, 99(2), 349-353.

Lefort, S., Tomm, C., Sarria, J. C. F., \& Petersen, C. C. (2009). The excitatory neuronal network of the C2 barrel column in mouse primary somatosensory cortex. Neuron, 61(2), 301-316.

Leiser, S. C., \& Moxon, K. A. (2006). Relationship between physiological response type (RA and SA) and vibrissal receptive field of neurons within the rat trigeminal ganglion. Journal of Neurophysiology, 95(5), 3129-3145.

Leiser, S. C., \& Moxon, K. A. (2007). Responses of trigeminal ganglion neurons during natural whisking behaviors in the awake rat. Neuron, 53(1), 117-133.

Lichtenstein, S. H., Carvell, G. E., \& Simons, D. J. (1990). Responses of rat trigeminal ganglion neurons to movements of vibrissae in different directions. Somatosensory \& Motor Research, 7(1), 47-65.

Li, C. X., \& Waters, R. S. (1991). Organization of the mouse motor cortex studied by retrograde tracing and intracortical microstimulation (ICMS) mapping. The Canadian Journal of Neurological Sciences, 18(1), 28-38.

Li, N., Chen, T. W., Guo, Z. V., Gerfen, C. R., \& Svoboda, K. (2015). A motor cortex circuit for motor planning and movement. Nature, 519(7541), 51-56.

Li, N., Daie, K., Svoboda, K., \& Druckmann, S. (2016). Robust neuronal dynamics in premotor cortex during motor planning. Nature, 532(7600), 459-464.

Lima, S. Q., Hromádka, T., Znamenskiy, P., \& Zador, A. M. (2009). PINP: a new method of tagging neuronal populations for identification during in vivo electrophysiological recording. PloS one, 4(7), e6099.

Lottem, E., \& Azouz, R. (2011). A unifying framework underlying mechanotransduction in the somatosensory system. The Journal of Neuroscience, 31(23), 8520-8532.

Lovick, T. A. (1972). The behavioural repertoire of precollicular decerebrate rats. The Journal of Physiology, 226(2), 4P-6P. 
MacKay, D. M., \& McCulloch, W. S. (1952). The limiting information capacity of a neuronal link. The Bulletin of Mathematical Biophysics, 14(2), 127-135.

Maksimovic, S., Nakatani, M., Baba, Y., Nelson, A. M., Marshall, K. L., Wellnitz, S. A., Firozi, P., Woo, S. H., Ranade, S., Patapoutian, A., \& Lumpkin, E. A. (2014). Epidermal Merkel cells are mechanosensory cells that tune mammalian touch receptors. Nature, 509(7502), 617-621.

Ma, P. M. (1991). The barrelettes-architectonic vibrissal representations in the brainstem trigeminal complex of the mouse. I. Normal structural organization. The Journal of Comparative Neurology, 309(2), 161-199.

Margrie, T. W., Brecht, M., \& Sakmann, B. (2002). In vivo, low-resistance, whole-cell recordings from neurons in the anaesthetized and awake mammalian brain. Pflugers Archiv: European Journal of Physiology, 444(4), 491-498.

Matthews, D. W., Deschênes, M., Furuta, T., Moore, J. D., Wang, F., Karten, H. J., \& Kleinfeld, D. (2015). Feedback in the brainstem: An excitatory disynaptic pathway for control of whisking. Journal of Comparative Neurology, 523(6), 921-942.

McGuire, L. M., Telian, G., Laboy-Juárez, K. J., Miyashita, T., Lee, D. J., Smith, K. A., \& Feldman, D. E. (2016). Short time-scale sensory coding in S1 during discrimination of whisker vibrotactile sequences. PLoS Biology, 14(8), e1002549.

Mehta, S. B., Whitmer, D., Figueroa, R., Williams, B. A., \& Kleinfeld, D. (2007). Active spatial perception in the vibrissa scanning sensorimotor system. PLoS Biology, 5(2), e15.

Milne, A. O., \& Grant, R. A. (2014). Characterisation of whisker control in the California sea lion (Zalophus californianus) during a complex, dynamic sensorimotor task. Journal of Comparative Physiology. A, Neuroethology, sensory, neural, and behavioral physiology, 200(10), 871-879.

Mitchinson, B., Gurney, K. N., Redgrave, P., Melhuish, C., Pipe, A. G., Pearson, M., Gilhespy, I., \& Prescott, T. J. (2004). Empirically inspired simulated electro-mechanical model of the rat mystacial follicle-sinus complex. Proceedings of the Royal Society of London B: Biological Sciences, 271(1556), 2509-2516.

Mitchinson, B., Martin, C. J., Grant, R. A., \& Prescott, T. J. (2007). Feedback control in active sensing: rat exploratory whisking is modulated by environmental contact. Proceedings of the Royal Society B: Biological Sciences, 274(1613), 1035-1041.

Miyashita, E., Keller, A., \& Asanuma, H. (1994). Input-output organization of the rat vibrissal motor cortex. Experimental Brain Research, 99(2), 223-232.

Montemurro, M. A., Panzeri, S., Maravall, M., Alenda, A., Bale, M., Brambilla, M., \& Petersen, R. S. (2007). Role of precise spike timing in coding of dynamic vibrissa stimuli in somatosensory thalamus. Journal of neurophysiology, 98(4), 1871-1882. 
Moore, J. D., Deschênes, M., Furuta, T., Huber, D., Smear, M. C., Demers, M., \& Kleinfeld, D. (2013). Hierarchy of orofacial rhythms revealed through whisking and breathing. Nature, 497(7448), 205-210.

Moore, J. D., Lindsay, N. M., Deschênes, M., \& Kleinfeld, D. (2015). Vibrissa self-motion and touch are reliably encoded along the same somatosensory pathway from brainstem through thalamus. PLoS Biology, 13(9), e1002253.

Moore, J. D., Kleinfeld, D., \& Wang, F. (2014). How the brainstem controls orofacial behaviors comprised of rhythmic actions. Trends in Neurosciences, 37(7), 370-380.

Mountcastle, V. B. (1997). The columnar organization of the neocortex. Brain: A Journal of Neurology, 120(4), 701-722.

Nashaat, M. A., Oraby, H., Peña, L. B., Dominiak, S., Larkum, M. E., \& Sachdev, R. N. (2017). Pixying behavior: A versatile real-time and post hoc automated optical tracking method for freely moving and head fixed animals. eNeuro, 4(1).

Nelder, J. A., \& Wedderburn, R. (1972). Generalized linear models. Journal of the Royal Statistical Society Series A, 135(3), 370-384.

Nguyen, Q.-T., \& Kleinfeld, D. (2005). Positive feedback in a brainstem tactile sensorimotor loop. Neuron, 45(3), 447-457.

O’Connor, D. H., Peron, S. P., Huber, D., \& Svoboda, K. (2010). Neural activity in barrel cortex underlying vibrissa-based object localization in mice. Neuron, 67(6), 1048-1061.

O’Connor, D. H., Hires, S. A., Guo, Z. V., Li, N., Yu, J., Sun, Q. Q., Huber, D., \& Svoboda, K. (2013). Neural coding during active somatosensation revealed using illusory touch. $\mathrm{Na}$ ture Neuroscience, 16(7), 958-965.

O'Connor, D. H., Clack, N. G., et al. (2010). Vibrissa-based object localization in headfixed mice. The Journal of Neuroscience, 30(5), 1947-1967.

Pammer, L., O'Connor, D. H., Hires, S. A., Clack, N. G., Huber, D., Myers, E. W., \& Svoboda, K. (2013). The mechanical variables underlying object localization along the axis of the whisker. The Journal of Neuroscience, 33(16), 6726-6741.

Paninski, L. (2004). Maximum likelihood estimation of cascade point-process neural encoding models. Network: Computation in Neural Systems, 15(4), 243-262.

Panzeri, S., Senatore, R., Montemurro, M. A., \& Petersen, R. S. (2007). Correcting for the sampling bias problem in spike train information measures. Journal of Neurophysiology, 98(3), 1064-1072.

Panzeri, S., Petersen, R. S., Schultz, S. R., Lebedev, M., \& Diamond, M. E. (2001). The role of spike timing in the coding of stimulus location in rat somatosensory cortex. Neuron, 29(3), 769-777. 
Panzeri, S., Pola, G., \& Petersen, R. S. (2003). Coding of sensory signals by neuronal populations: The role of correlated activity. The Neuroscientist: A Review Journal Bringing Neurobiology, Neurology and Psychiatry, 9(3), 175-180.

Pearson, M. J., Mitchinson, B., Sullivan, J. C., Pipe, A. G., \& Prescott, T. J. (2011). Biomimetic vibrissal sensing for robots. Philosophical transactions of the Royal Society of London, Series B, Biological Sciences, 366(1581), 3085-3096.

Perkon, I., Kosir, A., Itskov, P. M., Tasic, J. F., \& Diamond, M. E. (2011). Unsupervised quantification of whisking and head movement in freely moving rodents. Journal of Neurophysiology, 105(4), 1950-1962.

Peron, S. P., Freeman, J., Iyer, V., Guo, C., \& Svoboda, K. (2015). A cellular resolution map of barrel cortex activity during tactile behavior. Neuron, 86(3), 783-799.

Petersen, R. S., Brambilla, M., Bale, M. R., Alenda, A., Panzeri, S., Montemurro, M. A., \& Maravall, M. (2008). Diverse and temporally precise kinetic feature selectivity in the VPm thalamic nucleus. Neuron, 60(5), 890-903.

Petersen, R. S. (2013). The role of temporal spike patterns in neural codes. Principles of neural coding (Eds. S Panzeri, and R Quiroga), 339-356.

Petersen, R. S., \& Diamond, M. E. (2001). Topographic maps in the brain. John Wiley.

Petersen, R. S., Panzeri, S., \& Diamond, M. E. (2001). Population coding of stimulus location in rat somatosensory cortex. Neuron, 32(3), 503-514.

Petersen, R. S., Panzeri, S., \& Diamond, M. E. (2002). The role of individual spikes and spike patterns in population coding of stimulus location in rat somatosensory cortex. Bio Systems, 67(1-3), 187-193.

Petersen, R. S., Panzeri, S., \& Maravall, M. (2009). Neural coding and contextual influences in the whisker system. Biological Cybernetics, 100(6), 427-446.

Petreanu, L., Gutnisky, D. A., Huber, D., Xu, N. L., O’connor, D. H., Tian, L., Looger, L., \& Svoboda, K. (2012). Activity in motor-sensory projections reveals distributed coding in somatosensation. Nature, 489(7415), 299-303.

Pillow, J. W., Shlens, J., Paninski, L., Sher, A., Litke, A. M., Chichilnisky, E. J., \& Simoncelli, E. P. (2008). Spatio-temporal correlations and visual signalling in a complete neuronal population. Nature, 454(7207), 995-999.

Pinto, D. J., Hartings, J. A., Brumberg, J. C., \& Simons, D. J. (2003). Cortical damping: Analysis of thalamocortical response transformations in rodent barrel cortex. Cerebral Cortex, 13(1), 33-44.

Pinto, D. J., Brumberg, J. C., \& Simons, D. J. (2000). Circuit dynamics and coding strategies in rodent somatosensory cortex. Journal of Neurophysiology, 83(3), 1158-1166. 


\section{Sensing the Environment With Whiskers}

Prescott, T. J., Diamond, M. E., \& Wing, A. M. (2011). Active touch sensing. Philosophical Transactions of the Royal Society of London, Series B, Biological Sciences, 366(1581), 2989-2995.

Pubols, B. H. (1982). Factors affecting cutaneous mechanoreceptor response. I. Constantforce versus constant-displacement stimulation. Journal of Neurophysiology, 47(3), 515529.

Quist, B. W., Seghete, V., Huet, L. A., Murphey, T. D., \& Hartmann, M. J. (2014). Modeling forces and moments at the base of a rat vibrissa during noncontact whisking and whisking against an object. Journal of Neuroscience, 34(30), 9828-9844.

Quist, B. W., Faruqi, R. A. \& Hartmann, M. J. Z. (2011). Variation in Young's modulus along the length of a rat vibrissa. Journal of Biomechanics, 44(16), 2775-2781.

Ramirez, A., Pnevmatikakis, E. A., Merel, J., Paninski, L., Miller, K. D., \& Bruno, R. M., 2014. Spatiotemporal receptive fields of barrel cortex revealed by reverse correlation of synaptic input. Nature Neuroscience, 17(6), 866-875.

Ranade, S. S., Woo, S. H., Dubin, A. E., Moshourab, R. A., Wetzel, C., Petrus, M., Mathur, J., Bégay, V., Coste, B., Mainquist, J., \& Wilson, A. J. (2014). Piezo2 is the major transducer of mechanical forces for touch sensation in mice. Nature, 516(7529), 121-125.

Reep, R., \& Sarko, D. K. (2009). Tactile hair in Manatees. Scholarpedia Journal, 4(4), 6831.

Rice, F. L., Mance, A., \& Munger, B. L. (1986). A comparative light microscopic analysis of the sensory innervation of the mystacial pad. I. Innervation of vibrissal follicle-sinus complexes. The Journal of Comparative Neurology, 252(2), 154-174.

Rieke, F., Warland, D., van Steveninck, R. D. R., \& Bialek, W. (1999). Spikes: Exploring the neural code. Cambridge, MA: MIT Press.

Ritt, J. T., Andermann, M. L., \& Moore, C. I. (2008). Embodied information processing: Vibrissa mechanics and texture features shape micromotions in actively sensing rats. Neuron, 57(4), 599-613.

Rushton, S. K., \& Warren, P. A. (2005). Moving observers, relative retinal motion and the detection of object movement. Current Biology, 15(14), R542-R543.

Russell, R. A. (1985). Object recognition using articulated whisker probes. In Proceedings of the 15th International Symposium on Industrial Robots (Vol. 3, pp. 605-612). Tokyo, Japan: Japan Industrial Robot Association.

Semba, K., \& Komisaruk, B. R. (1984). Neural substrates of two different rhythmical vibrissal movements in the rat. Neuroscience, 12(3), 761-774. 
Severson, K. S., Xu, D., Van de Loo, M., Bai, L., Ginty, D. D., \& O’Connor, D. H. (2017). Active touch and self-motion encoding by Merkel cell-associated afferents. Neuron, 94(3), 666-676.

Shannon, C. E. (1948). A mathematical theory of communication, Part I, Part II. Bell System Technical Journal, 27, 623-656.

Sharp, T., Petersen, R., \& Furber, S. (2014). Real-time million-synapse simulation of rat barrel cortex. Frontiers in Neuroscience, 8, 131.

Shoykhet, M., Doherty, D., \& Simons, D. J. (2000). Coding of deflection velocity and amplitude by whisker primary afferent neurons: Implications for higher level processing. Somatosensory \& Motor Research, 17(2), 171-180.

Simons, D. J. (1995). Neuronal integration in the somatosensory whisker/barrel cortex. In The barrel cortex of rodents: Cerebral cortex (pp. 263-297). Boston, MA: Springer.

Simony, E., Bagdasarian, K., Herfst, L., Brecht, M., Ahissar, E., \& Golomb, D. (2010). Temporal and spatial characteristics of vibrissa responses to motor commands. The Journal of Neuroscience, 30(26), 8935-8952.

Sofroniew, N. J., Cohen, J. D., Lee, A. K., \& Svoboda, K. (2014). Natural whisker-guided behavior by head-fixed mice in tactile virtual reality. The Journal of Neuroscience, 34(29), 9537-9550.

Solomon, J. H., \& Hartmann, M. J. (2006). Biomechanics: Robotic whiskers used to sense features. Nature, 443(7111), 525.

Storchi, R., Bale, M. R., Biella, G. E. M., \& Petersen, R. S. (2012). Comparison of latency and rate coding for the direction of whisker deflection in the subcortical somatosensory pathway. Journal of Neurophysiology, 108(7), 1810-1821.

Stosiek, C., Garaschuk, O., Holthoff, K., \& Konnerth, A. (2003). In vivo two-photon calcium imaging of neuronal networks. Proceedings of the National Academy of Sciences, 100(12), 7319-7324.

Svoboda, K., Denk, W., Kleinfeld, D., \& Tank, D. W. (1997). In vivo dendritic calcium dynamics in neocortical pyramidal neurons. Nature, 385(6612), 161-165.

Szwed, M., Bagdasarian, K., Blumenfeld, B., Barak, O., Derdikman, D., \& Ahissar, E. (2006). Responses of trigeminal ganglion neurons to the radial distance of contact during active vibrissal touch. Journal of Neurophysiology, 95(2), 791-802.

Szwed, M., Bagdasarian, K., \& Ahissar, E. (2003). Encoding of vibrissal active touch. Neuron, 40(3), 621-630. 
Takatoh, J., Nelson, A., Zhou, X., Bolton, M. M., Ehlers, M. D., Arenkiel, B. R., Mooney, R., \& Wang, F. (2013). New modules are added to vibrissal premotor circuitry with the emergence of exploratory whisking. Neuron, 77(2), 346-360.

Takatoh, J., Prevosto, V., \& Wang, F. (2017). Vibrissa sensory neurons: Linking distinct morphology to specific physiology and function. Neuroscience.

Thé, L., Wallace, M. L., Chen, C. H., Chorev, E., \& Brecht, M. (2013). Structure, function, and cortical representation of the rat submandibular whisker trident. The Journal of Neuroscience, 33(11), 4815-4824.

Tonomura, S., Ebara, S., Bagdasarian, K., Uta, D., Ahissar, E., Meir, I., Lampl, I., Kuroda, D., Furuta, T., Furue, H., \& Kumamoto, K. (2015). Structure-function correlations of rat trigeminal primary neurons: Emphasis on club-like endings, a vibrissal mechanoreceptor. Proceedings of the Japan Academy: Series B, Physical and Biological Sciences, 91(10), 560-576.

Towal, R. B., \& Hartmann, M. J. (2006). Right-left asymmetries in the whisking behavior of rats anticipate head movements. The Journal of Neuroscience, 26(34), 8838-8846.

Truccolo, W., Eden, U. T., Fellows, M. R., Donoghue, J. P., \& Brown, E. N. (2005). A point process framework for relating neural spiking activity to spiking history, neural ensemble, and extrinsic covariate effects. Journal of Neurophysiology, 93(2), 1074-1089.

Urbain, N., Salin, P. A., Libourel, P. A., Comte, J. C., Gentet, L. J., \& Petersen, C. C. (2015). Whisking-related changes in neuronal firing and membrane potential dynamics in the somatosensory thalamus of awake mice. Cell Reports, 13(4), 647-656.

van der Loos, H. (1976). Barreloids in mouse somatosensory thalamus. Neuroscience Letters, 2(1), 1-6.

van der Loos, H., \& Dörfl, J. (1978). Does the skin tell the somatosensory cortex how to construct a map of the periphery? Neuroscience Letters, 7(1), 23-30.

Venkatraman, S., Elkabany, K., Long, J. D., Yao, Y., \& Carmena, J. M. (2009). A system for neural recording and closed-loop intracortical microstimulation in awake rodents. IEEE Transactions on Bio-medical Engineering, 56(1), 15-22.

Vincent, S. B. (1912). The functions of the vibrissae in the behavior of the white rat. Chicago, IL: University of Chicago.

Voigts, J., Sakmann, B., \& Celikel, T. (2008). Unsupervised whisker tracking in unrestrained behaving animals. Journal of Neurophysiology, 100(1), 504-515.

Wallach, A., Bagdasarian, K., \& Ahissar, E. (2016). On-going computation of whisking phase by mechanoreceptors. Nature Neuroscience, 19(3), 487. 
Welker, E. \& van der Loos, H. (1986). Quantitative correlation between barrel-field size and the sensory innervation of the whiskerpad: A comparative study in six strains of mice bred for different patterns of mystacial vibrissae. Journal of Neuroscience, 6(11), 33553373.

Welker, W. I. (1964). Analysis of sniffing of the Albino rat 1. Behaviour, 22(3), 223-244.

Whiteley, S. J., Knutsen, P. M., Matthews, D. W., \& Kleinfeld, D. (2015). Deflection of a vibrissa leads to a gradient of strain across mechanoreceptors in a mystacial follicle. Journal of Neurophysiology, 114(1), 138-145.

Wolfe, J., Hill, D. N., Pahlavan, S., Drew, P. J., Kleinfeld, D., \& Feldman, D. E. (2008). Texture coding in the rat whisker system: Slip-stick versus differential resonance. PLoS Biology, 6(8), e215.

Wolfe, J., Mende, C., \& Brecht, M. (2011). Social facial touch in rats. Behavioral Neuroscience, 125(6), 900-910.

Woolsey, T. A., \& van der Loos, H. (1970). The structural organization of layer IV in the somatosensory region (SI) of mouse cerebral cortex. The description of a cortical field composed of discrete cytoarchitectonic units. Brain Research, 17(2), 205-242.

Woo, S. H., Ranade, S., Weyer, A. D., Dubin, A. E., Baba, Y., Qiu, Z., Petrus, M., Miyamoto, T., Reddy, K., Lumpkin, E. A., \& Stucky, C. L. (2014). Piezo2 is required for Merkel-cell mechanotransduction. Nature, 509(7502), 622-626.

Xu, N. L., Harnett, M. T., Williams, S. R., Huber, D., O’connor, D. H., Svoboda, K., \& Magee, J. C. (2012). Nonlinear dendritic integration of sensory and motor input during an active sensing task. Nature, 492(7428), 247-251.

Yang, H., Kwon, S. E., Severson, K. S., \& O’Connor, D. H. (2016). Origins of choice-related activity in mouse somatosensory cortex. Nature Neuroscience, 19(1), 127-134.

Yarbus, A. L. (1967). Eye movements during perception of complex objects. In Eye movements and vision (pp. 171-211). Boston, MA: Springer.

Yu, C., Derdikman, D., Haidarliu, S., \& Ahissar, E. (2006). Parallel thalamic pathways for whisking and touch signals in the rat. PLoS Biology, 4(5), e124.

Yu, J., Gutnisky, D. A., Hires, S. A., \& Svoboda, K. (2016). Layer 4 fast-spiking interneurons filter thalamocortical signals during active somatosensation. Nature Neuroscience.

Yan, S. W., Graff, M. M., Bresee, C. S., Man, Y. B., \& Hartmann, M. J. (2016). Whiskers aid anemotaxis in rats. Science Advances, 2(8), e1600716.

Zucker, E., \& Welker, W. I. (1969). Coding of somatic sensory input by vibrissae neurons in the rat's trigeminal ganglion. Brain Research, 12(1), 138-156. 
Zuo, Y., Safaai, H., Notaro, G., Mazzoni, A., Panzeri, S., \& Diamond, M. E. (2015). Complementary contributions of spike timing and spike rate to perceptual decisions in rat $\mathrm{S} 1$ and S2 cortex. Current Biology, 25(3), 357-363.

\section{Mathew H. Evans}

University of Manchester

Michaela S.E. Loft

University of Manchester

\section{Dario Campagner}

University of Manchester

\section{Rasmus S. Petersen}

University of Manchester 